Research papers

\title{
Comparison of thermal, salt and dye tracing to estimate shallow flow velocities: Novel triple-tracer approach
}

\author{
João R.C.B. Abrantes ${ }^{\mathrm{a}, \mathrm{b}, *}$, Rodrigo B. Moruzzi ${ }^{\mathrm{c}}$, Alexandre Silveira ${ }^{\mathrm{a}, \mathrm{d}}$, João L.M.P. de Lima ${ }^{\mathrm{a}, \mathrm{b}}$ \\ ${ }^{a}$ MARE - Marine and Environmental Sciences Centre, Coimbra, Portugal \\ ${ }^{\mathrm{b}}$ Department of Civil Engineering, Faculty of Sciences and Technology, University of Coimbra, Coimbra, Portugal \\ ${ }^{\mathrm{c}}$ Geoprocessing and Territorial Planning Department, Geosciences and Mathematics Institute, UNESP - Univ Estadual Paulista, Rio Claro, SP, Brazil \\ ${ }^{\mathrm{d}}$ Institute of Science and Technology, Federal University of Alfenas, Poços de Caldas, MG, Brazil
}

\section{A R T I C L E I N F O}

\section{Article history:}

Received 29 July 2017

Received in revised form 6 November 2017

Accepted 18 December 2017

Available online 20 December 2017

This manuscript was handled by Marco

Borga, Editor-in-Chief, with the assistance of

Yasuto Tachikawa, Associate Editor

\section{Keywords:}

Thermal tracer

Salt tracer

Dye tracer

Flow velocity

Correction factor

Laboratory experiment

\begin{abstract}
A B S T R A C T
The accurate measurement of shallow flow velocities is crucial to understand and model the dynamics of sediment and pollutant transport by overland flow. In this study, a novel triple-tracer approach was used to re-evaluate and compare the traditional and well established dye and salt tracer techniques with the more recent thermal tracer technique in estimating shallow flow velocities. For this purpose a triple tracer (i.e. dyed-salted-heated water) was used. Optical and infrared video cameras and an electrical conductivity sensor were used to detect the tracers in the flow. Leading edge and centroid velocities of the tracers were measured and the correction factors used to determine the actual mean flow velocities from tracer measured velocities were compared and investigated. Experiments were carried out for different flow discharges (32-1813 $\mathrm{ml} \mathrm{s}^{-1}$ ) on smooth acrylic, sand, stones and synthetic grass bed surfaces with $0.8,4.4$ and $13.2 \%$ slopes. The results showed that thermal tracers can be used to estimate shallow flow velocities, since the three techniques yielded very similar results without significant differences between them. The main advantages of the thermal tracer were that the movement of the tracer along the measuring section was more easily visible than it was in the real image videos and that it was possible to measure space-averaged flow velocities instead of only one velocity value, with the salt tracer. The correction factors used to determine the actual mean velocity of overland flow varied directly with Reynolds and Froude numbers, flow velocity and slope and inversely with flow depth and bed roughness. In shallow flows, velocity estimation using tracers entails considerable uncertainty and caution must be taken with these measurements, especially in field studies where these variables vary appreciably in space and time.
\end{abstract}

(c) 2017 Elsevier B.V. All rights reserved.

\section{Introduction}

Flow velocity is a basic hydraulic property of shallow flows (e.g. overland flow, rill flow, stream flow) and most hydroenvironmental research relies on its accurate measurement (e.g. Govers, 1992; Takken and Govers 2000; Giménez et al., 2004). Shallow flows can occur in natural and urbanized basins (e.g. hillslopes, drainage systems) and their characterization is crucial for runoff, erosion and water quality modelling (e.g. Kreibich et al., 2009; Mügler et al., 2011).

Flow velocity measuring techniques vary with water body dimension, its accessibility and characteristics. Recently, signifi-

* Corresponding author at: Department of Civil Engineering, Faculty of Sciences and Technology of the University of Coimbra (DEC-FCTUC), Rua Luís Reis Santos, Pólo II - Universidade de Coimbra, 3030-788 Coimbra, Portugal.

E-mail address: jrcbrito@msn.com (J.R.C.B. Abrantes). cant developments have been made in sensing technology, resulting in a wide spectrum of powerful and versatile options for high accuracy flow velocity data. However, measurement devices may have some limitations when operating outside their ideal measurement conditions. Particularly for shallow flows, the characterization of the velocity fields is complicated, mostly because of their lack of depth (anything from several millimetres to a few centimetres) and other problems, such as variability of the channel bed due to erosion, presence of sediment and other debris in the flow or even the presence of vegetation concealing the measuring area. This restricts the use of many flow measuring devices.

For deeper water bodies (e.g. large rivers) flow velocity can be measured with current metres or acoustic Doppler techniques, such as acoustic Doppler velocimetry (ADV) or acoustic Doppler current profiler (ADCP), at determined monitoring sections (e.g. Muste et al., 2004a,b; Kimiaghalam et al., 2016). Although 
intrusive, these techniques do provide a reliable characterization of the flow velocity vertical profile; however, these instruments cannot always be used in very shallow water. Other techniques, such as satellites, radars and microwave sensors, hand-held or coupled in a drone, can be used to estimate surface flow velocity accurately and non-intrusively (e.g. Bjerklie et al., 2003; Bjerklie, 2007; Fulton and Ostrowski, 2008); however, these methods are usually very costly and satellite data are typically applied to large water bodies.

For a long time, less accurate and less costly techniques used for shallow flow velocity measurements were based on determining the travel time of a tracer across a predefined section. In fact, many researchers regard tracer methods as crude methods that yield a maximum flow velocity that has to be corrected to give a mean velocity. However, in shallow muddy flows, with depths of a few millimetres to a few centimetres, it is not always possible to use the more sophisticated methods to measure true mean flow velocity, such as ADV, ACDP. When using tracers, the accuracy of the measurement depends to a great extent on the tracer added to the flow and on the quality of its detection in the flow. According to Flury and Wai (2003) an ideal tracer for hydro-environmental research should: i) have movement similar to water; ii) be conservative, i.e. without degradation during the measurement time; iii) not show sorption to other environment components (e.g. soil, sediments, rocks); iv) be clearly distinguishable from the background of the system; v) be detectable either by chemical analysis or by visualization; vi) low toxicological impact on the study environment. Among the different materials that have been tested as tracers in flow velocity experiments are natural and radioactive isotopes (Niazi et al., 2017), floating objects (Tauro et al., 2012a), fluorescent particles (Tauro et al., 2012b,c), bacteria (e.g. Maurice et al. 2010), salts (e.g. Calkins and Dunne, 1970; Day, 1977; Lei et al., 2005, 2010; Shi et al., 2012) and dyes (e.g. Abrahams et al., 1986; Flury and Flühler, 1993; Dunkerley, 2003; Holden et al., 2008; Tazioli, 2011). Depending on the used tracer, optical cameras (e.g. for dyes, floating objects), fluorometers (e.g. for fluorescent particles, fluorescent dyes) or electrical conductivity sensors (e.g. for salt tracers), can be used. A review of tracer technology in hydrologic studies is presented in Leibundgut et al. (2009). A more recent approach uses thermal tracers (e.g. water hotter or colder than the flow) that can be detected by infrared sensor equipment (e.g. infrared video camera). Thermal tracers were tested as instruments to measure flow velocities (Schuetz et al., 2012; de Lima and Abrantes, 2014b; de Lima et al., 2015; Bonner et al., 2017), as well as for assessing microrelief (Abrantes and de Lima, 2014; de Lima and Abrantes 2014a), permeability (de Lima et al., 2014b), macroporosity (de Lima et al., 2014a,c) and repellency of the soil surface (Abrantes et al., 2016, 2017).

Traditionally, estimation of the mean flow velocity using tracers would consist of measuring the time from the injection of the tracer to its arrival at a sampling point and then dividing this figure by the travel distance. With dye tracers, the leading edge velocity is usually measured, since it is frequently regarded as the surface velocity of the flow. With salt tracers, the leading edge, peak or centroid of the tracer's concentration at the sampling point are measured. The leading edge is regarded as the surface velocity of the flow and the peak and centroid can be labelled as mean theoretical velocities, if retention of the salt in the water flow is assumed. However, especially in soil erosion processes, there can be constant exchanges of salt between the soil surface and water flow as the soil absorbs the salts, or the salts are dissolved from the detached soil materials. Also, infiltration processes lead to a decrease in the total amount of salt at the sampling point. Therefore, none of the measured velocities are considered the actual mean velocity of the flow. A correction factor has to be applied to obtain the mean flow velocity (e.g. Horton et al., 1934). This correction factor varies with the flow characteristics such as velocity, depth, Reynolds number and Froude number, with the concentration of sediments in the flow and with the bed surface characteristics such as slope and roughness (Emmett, 1970; Li et al., 1996; Li and Abrahams, 1997; Dunkerley, 2001; Planchon et al., 2005; Zhang et al., 2010).

Optical methods for flow characterization, such as particle image velocimetry (PIV) and particle tracking velocimetry (PTV), have seen great development and have been adjusted so that they can be used in natural environments (e.g. Coz et al., 2010; Kantoush et al., 2011, Tauro et al., 2014, 2016). These methods combine digital cameras and lasers to track the movement of particles dispersed in the water (e.g. fluorescent particles, air bubbles, floating objects) and thereby estimate the surface flow velocity. Based on these optical methods, Tauro and Grimaldi (2017) used an infrared camera to track thermal particles (ice cubes) to monitor stream surface velocity.

In the present study, laboratory experiments were conducted to compare the traditional dye and salt tracer techniques to the more recent thermal tracer technique for estimating shallow flow velocities and investigating the effects of a wide range of hydraulic conditions on the correction factor used to determine mean flow velocity. This was done by adding a triple tracer (i.e. dyed-saltedheated water) into shallow flows and detecting its passage with optical and infrared video cameras and an electrical conductivity sensor. Experiments were carried out considering different bed surfaces (smooth acrylic, sand, stones and synthetic grass), flow discharges (32-1813 $\mathrm{ml} \mathrm{s}^{-1}$ ) and bed slopes (0.8, 4.4 and $13.2 \%$ ), resulting in flow velocities from 0.02 to $0.85 \mathrm{~m} \mathrm{~s}^{-1}$, flow depths from 1.4 to $46.0 \mathrm{~mm}$, Reynolds numbers from 785 to 19,000 and Froude numbers from 0.05 to 4.66 . For the salt and thermal tracers, leading edge and centroid velocities of the tracers were measured. For the dye tracer, only the leading edge velocity was measured. Correction factors used to determine mean flow velocity were calculated by comparing triple-tracer measured velocities with velocities calculated from measured discharges and flow depths. This novel triple-tracer approach can give insight into the measurement of shallow flow velocities and provide a useful tool to re-evaluate and compare the three techniques.

\section{Material and methods}

\subsection{Hydraulic channel and simulated flows}

Dye, salt and thermal tracer techniques were compared using the laboratory setup schematized in Fig. 1. It comprised a hydraulic channel $3.00 \mathrm{~m}$ long and $0.15 \mathrm{~m}$ wide that uses a water recirculation circuit with a $500 \mathrm{~L}$ reservoir, a pump and a flow control valve. The channel bed and walls are made of smooth, transparent acrylic sheets, and are thus impermeable. The setup allows a manual adjustment of the bed slope. The channel has free inflow and outflow and so flow velocity and flow depth are controlled by the flow discharge, bed slope and bed surface roughness.

Shallow flow velocity measurements were taken on four different bed surfaces, as shown in Fig. 2: i) smooth acrylic; ii) sand; iii) stones; and iv) synthetic grass. Smooth acrylic tests were performed on the smooth, transparent acrylic sheet of the channel bed. For the sand tests, $<1.2 \mathrm{~mm}$ sieved sand particles were homogeneously glued to an acrylic board that was placed over the channel bed. Stone tests were performed by uniformly distributing 10$20 \mathrm{~mm}$ sieved stones over the channel bed. For the last tests, an $8.5 \mathrm{~mm}$ height synthetic grass carpet was fixed to the channel bed. Three bed slopes of $0.8,4.4$ and $13.2 \%$ were considered for each surface.

Flow velocity was measured for a total of 32 different flow conditions, combining four bed surfaces, three bed slopes and different 


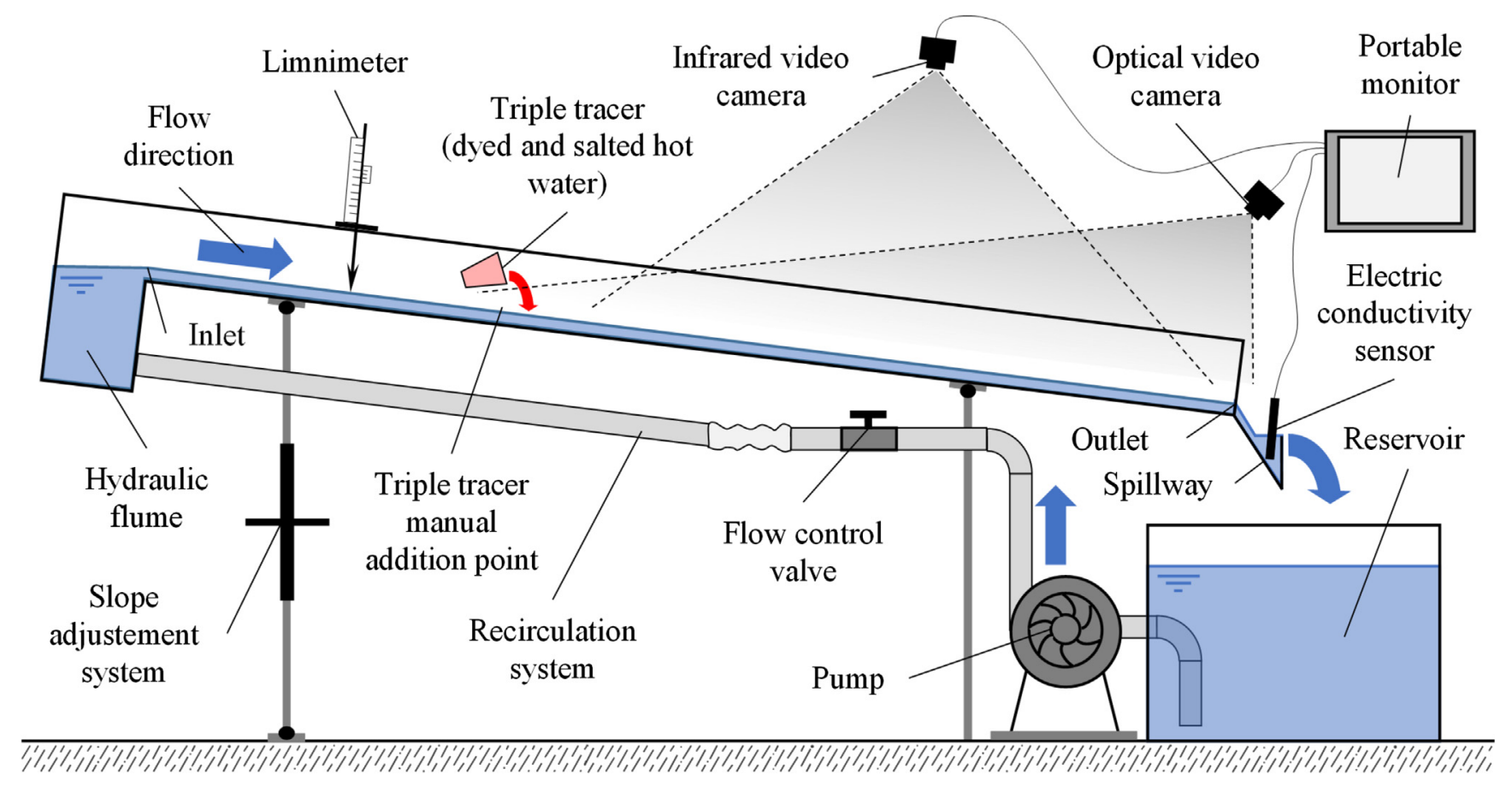

Fig. 1. Scheme (side view) of the laboratory setup used in the triple-tracer experiments.

flow discharges, as summarized in Table 1. For each flow condition, flow velocity was measured in triplicate, using the triple tracer, and flow depth was measured using a precision limnimeter. Flow discharge was controlled manually by the flow control valve in the recirculation system and was measured at the channel outlet by the volumetric method.

At the end of each set of tests (i.e. when bed surface was changed) the water from the reservoir was removed and replaced for fresh water to avoid excessive accumulation of the tracers' concentration in the recirculating water and avoid affecting the precision of the flow velocity measurements: during the experiments, average flow water temperature and electric conductivity varied between 28.0 and $31.9^{\circ} \mathrm{C}$ and $198-445 \mu \mathrm{S} \mathrm{cm}^{-1}$, respectively.

\subsection{Triple tracer}

To be able to compare shallow flow velocities measured with dye, salt and thermal tracers, the three techniques were tested simultaneously in a triple tracer combining dyed-salted-heated water. This was made by adding dye and common table salt to tap water and heating this solution to a temperature well above the average flow water temperature. Common food colouring solutions (E104 yellow quinolone, E122 red carmoisine, E133 brilliant blue FCF and E147 green) and common table salt, in a ratio of 50 $\mathrm{g}$ of dye and $5 \mathrm{~g}$ of salt per litre of water, were used. These concentrations were established in preliminary tests and shown to be detectable in the flow either by visualization (dye tracer) or by the electrical conductivity sensor (salt tracer). Average tracer temperature immediately before addition to the flow was $71.3 \pm 5.2^{\circ} \mathrm{C}$. This was after heating the tracer in an electric kettle to boiling point and transferring it to a cup for adding to the flow. Any differences between flow and tracer density and viscosity due to differences in temperature, salt and dye concentrations should be minimal and should not have a significant influence on the transport of the triple tracer in the flow.

A volume of $10 \mathrm{ml}$ of triple tracer per $100 \mathrm{ml} \mathrm{s}^{-1}$ of flow discharge was used in each flow velocity measurement. This ratio of tracer to flow discharge was appropriate for enabling the triple tra- cer to be detected in the flow with the three techniques. Also, in de Lima and Abrantes (2014b), this ratio showed minor differences between flow velocities measured with thermal and dye tracers. The triple tracer was manually added to the flow in a quick movement, $2.1 \mathrm{~m}$ upslope of the channel outlet (as shown in Fig. 1) and half-way across it.

\subsection{Tracer detection systems}

The movement of the triple tracer in the flow was recorded with an infrared and a real image video camera and was detected with an electrical conductivity sensor at a spillway installed next to the outlet. The videos and the electrical conductivity were all monitored by portable devices throughout the experiments.

\subsubsection{Infrared video camera}

Thermal videos were recorded with an Optris PI-160 infrared video camera (from Optris $\mathrm{GmbH}$, Germany) and monitored on a laptop using PI Connect software (from Optris GmbH, Germany). The infrared video camera has an optical resolution of $160 \times 120$ pixels, a thermal resolution of $0.1^{\circ} \mathrm{C}$, an accuracy of $\pm 2 \%$, a frame rate of $120 \mathrm{~Hz}$, a lens with a field of view of $23^{\circ} \times 17^{\circ}$ and covers the spectral range of $7.5-13.0 \mu \mathrm{m}$. The camera was fixed to a metal structure $4 \mathrm{~m}$ above the channel bed, with the focal direction perpendicular to the soil surface to ensure minimum angular distortion. The field of view covered $1.6 \mathrm{~m}$ of the channel bed in the flow direction (0.1-1.7 m upslope of the outlet and $0.4-2.0 \mathrm{~m}$ downslope of the triple tracer addition point) and the entire width of $0.15 \mathrm{~m}$, providing thermal imaging with $156 \times 13$ pixels.

\subsubsection{Electrical conductivity sensor}

Electrical conductivity was monitored with a CON-BTA conductivity sensor (from Vernier Software \& Technology LLC, USA) using the respective LabQuest portable interface (from Vernier Software \& Technology LLC, USA). The sensor was placed in a spillway installed next to the channel outlet. The spillway was used to produce a minimum water column of approximately $30 \mathrm{~mm}$ needed for the measurements. Electrical conductivity data was collected 

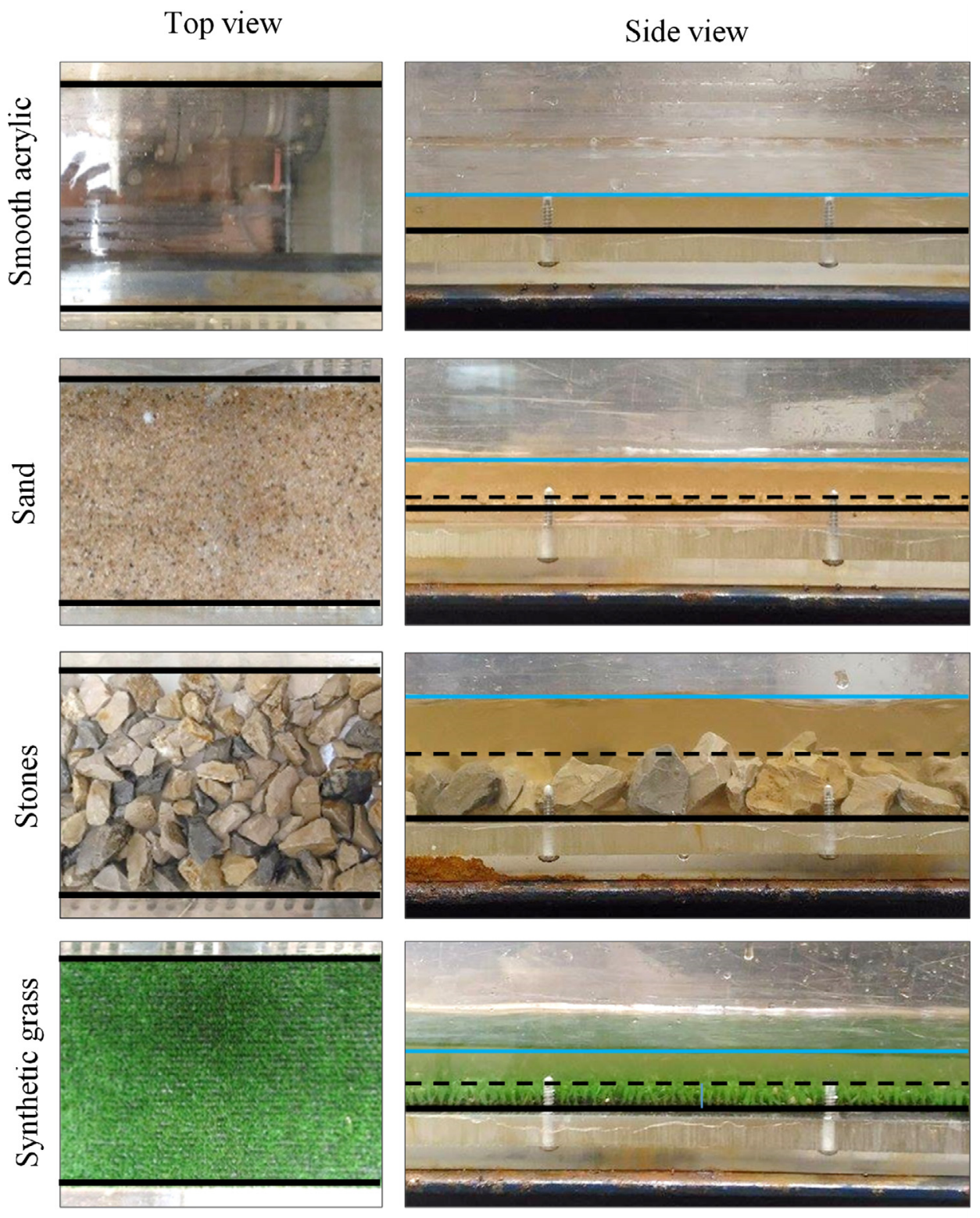

\section{$0.1 \mathrm{~m}$}

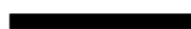

Channel bed and walls

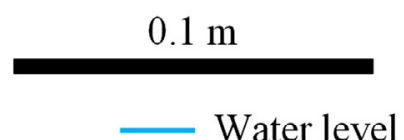

Water level

\section{- - Approximated roughness limit}

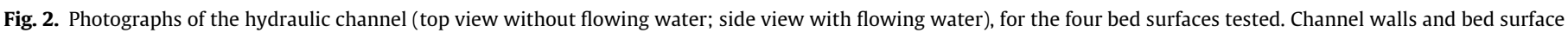
and approximate water levels and roughness limits are marked.

with a temporal resolution of $0.2 \mathrm{~s}$ in mid-channel of $0-2000 \mu \mathrm{S} /$ $\mathrm{cm}$, with an accuracy of $\pm 3 \%$. The sensor has an automatic mechanism for temperature compensation between 5 and $35^{\circ} \mathrm{C}$, enough to offset the temperature of the tracer observed at the channel outlet.

\subsubsection{Optical video camera}

Real image videos were recorded with a regular optical video camera GoPro Hero 3 (from GoPro Inc., USA) and monitored on a laptop using the product software GoPro Studio (from GoPro Inc., USA). The optical video camera has a digital resolution of $1920 \times$ 1080 pixels, a frame rate of $30 \mathrm{~Hz}$ and a lens with a field of view of $120^{\circ} \times 70^{\circ}$. The camera was attached to a metal structure with the focal direction diagonal to the channel bed to ensure good coverage of the point where the triple tracer was added to the flow, its movement along the channel and its exit via the outlet.

\subsection{Data analyses}

Thermal and real image videos and electrical conductivity data were analysed separately using proper software to estimate flow velocity and compare the three tracer techniques. For the thermal and salt tracers, flow velocity was estimated considering the leading edge and centroid of the tracers as they passed through the 
Table 1

Overall results of the triple tracer experiments.

\begin{tabular}{|c|c|c|c|c|c|c|c|c|}
\hline & \multirow{3}{*}{$\begin{array}{l}\text { Slope } \\
\text { S (\%) }\end{array}$} & \multirow{3}{*}{$\begin{array}{l}\text { DischargeQ } \\
(\mathrm{ml} / \mathrm{s})\end{array}$} & \multirow{3}{*}{$\begin{array}{l}\text { Mean flow velocityVm } \\
\left(\mathrm{m} \mathrm{s}^{-1}\right)\end{array}$} & \multicolumn{5}{|c|}{ Tracer velocity $\left(\mathrm{m} \mathrm{s}^{-1}\right)^{*}$} \\
\hline & & & & \multicolumn{2}{|l|}{ Thermal } & \multicolumn{2}{|l|}{ Salt } & \multirow{2}{*}{$\begin{array}{l}\text { Dye } \\
\text { Leading edge } \\
\text { Vdye }_{\mathrm{LE}}\end{array}$} \\
\hline & & & & $\begin{array}{l}\text { Leading edge } \\
\text { Vthe }_{\mathrm{LE}}\end{array}$ & $\begin{array}{l}\text { Centroid } \\
\text { Vthe }_{\mathrm{C}}\end{array}$ & $\begin{array}{l}\text { Leading edge } \\
\text { Vsal }_{\mathrm{LE}}\end{array}$ & $\begin{array}{l}\text { Centroid } \\
\text { Vsal }_{C}\end{array}$ & \\
\hline \multirow[t]{8}{*}{ Smooth acrylic } & 0.8 & 650 & 0.475 & $\begin{array}{l}0.608 \pm \\
0.013\end{array}$ & $\begin{array}{l}0.608 \pm \\
0.009\end{array}$ & $\begin{array}{l}0.596 \pm \\
0.033\end{array}$ & $\begin{array}{l}0.547 \pm \\
0.040\end{array}$ & $\begin{array}{l}0.559 \pm \\
0.008\end{array}$ \\
\hline & 0.8 & 856 & 0.516 & $\begin{array}{l}0.703 \pm \\
0.014\end{array}$ & $\begin{array}{l}0.684 \pm \\
0.010\end{array}$ & $\begin{array}{l}0.639 \pm \\
0.019\end{array}$ & $\begin{array}{l}0.547 \pm \\
0.047\end{array}$ & $\begin{array}{l}0.629 \pm \\
0.013\end{array}$ \\
\hline & 0.8 & 1158 & 0.580 & $\begin{array}{l}0.762 \pm \\
0.008\end{array}$ & $\begin{array}{l}0.772 \pm \\
0.020\end{array}$ & $\begin{array}{l}0.637 \pm \\
0.020\end{array}$ & $\begin{array}{l}0.597 \pm \\
0.027\end{array}$ & $\begin{array}{l}0.709 \pm \\
0.004\end{array}$ \\
\hline & 4.4 & 420 & 0.529 & $\begin{array}{l}0.645 \pm \\
0.012\end{array}$ & $\begin{array}{l}0.639 \pm \\
0.005\end{array}$ & $\begin{array}{l}0.595 \pm \\
0.043\end{array}$ & $\begin{array}{l}0.552 \pm \\
0.019\end{array}$ & $\begin{array}{l}0.585 \pm \\
0.016\end{array}$ \\
\hline & 4.4 & 696 & 0.623 & $\begin{array}{l}0.828 \pm \\
0.048\end{array}$ & $\begin{array}{l}0.791 \pm \\
0.016\end{array}$ & $\begin{array}{l}0.717 \pm \\
0.134\end{array}$ & $\begin{array}{l}0.649 \pm \\
0.071\end{array}$ & $\begin{array}{l}0.715 \pm \\
0.006\end{array}$ \\
\hline & 13.2 & 71 & 0.345 & $\begin{array}{l}0.572 \pm \\
0.058\end{array}$ & $\begin{array}{l}0.378 \pm \\
0.025\end{array}$ & $\begin{array}{l}0.591 \pm \\
0.009\end{array}$ & $\begin{array}{l}0.460 \pm \\
0.014\end{array}$ & $\begin{array}{l}0.540 \pm \\
0.015\end{array}$ \\
\hline & 13.2 & 164 & 0.619 & $\begin{array}{l}0.777 \pm \\
0.082\end{array}$ & $\begin{array}{l}0.683 \pm \\
0.015\end{array}$ & $\begin{array}{l}0.725 \pm \\
0.063\end{array}$ & $\begin{array}{l}0.573 \pm \\
0.030\end{array}$ & $\begin{array}{l}0.630 \pm \\
0.021\end{array}$ \\
\hline & 13.2 & 450 & 0.851 & $\begin{array}{l}1.036 \pm \\
0.018\end{array}$ & $\begin{array}{l}0.944 \pm \\
0.024\end{array}$ & $\begin{array}{l}0.901 \pm \\
0.095\end{array}$ & $\begin{array}{l}0.945 \pm \\
0.039\end{array}$ & $\begin{array}{l}0.944 \pm \\
0.027\end{array}$ \\
\hline \multirow[t]{6}{*}{ Sand } & 0.5 & 47 & 0.035 & $\begin{array}{l}0.092 \pm \\
0.002\end{array}$ & $\begin{array}{l}0.081 \pm \\
0.005\end{array}$ & $\begin{array}{l}0.080 \pm \\
0.008\end{array}$ & $\begin{array}{l}0.106 \pm \\
0.003\end{array}$ & n.a. \\
\hline & 0.5 & 81 & 0.070 & $\begin{array}{l}0.116 \pm \\
0.002\end{array}$ & $\begin{array}{l}0.121 \pm \\
0.007\end{array}$ & $\begin{array}{l}0.138 \pm \\
0.001\end{array}$ & $\begin{array}{l}0.108 \pm \\
0.006\end{array}$ & $\begin{array}{l}0.114 \pm \\
0.006\end{array}$ \\
\hline & 0.5 & 210 & 0.079 & $\begin{array}{l}0.172 \pm \\
0.005\end{array}$ & $\begin{array}{l}0.166 \pm \\
0.005\end{array}$ & $\begin{array}{l}0.156 \pm \\
0.015\end{array}$ & $\begin{array}{l}0.143 \pm \\
0.009\end{array}$ & $\begin{array}{l}0.163 \pm \\
0.004\end{array}$ \\
\hline & 4.4 & 72 & 0.033 & $\begin{array}{l}0.105 \pm \\
0.002\end{array}$ & $\begin{array}{l}0.102 \pm \\
0.005\end{array}$ & $\begin{array}{l}0.122 \pm \\
0.006\end{array}$ & $\begin{array}{l}0.095 \pm \\
0.004\end{array}$ & n.a. \\
\hline & 4.4 & 259 & 0.178 & $\begin{array}{l}0.332 \pm \\
0.009\end{array}$ & $\begin{array}{l}0.269 \pm \\
0.004\end{array}$ & $\begin{array}{l}0.317 \pm \\
0.001\end{array}$ & $\begin{array}{l}0.252 \pm \\
0.002\end{array}$ & $\begin{array}{l}0.343 \pm \\
0.003\end{array}$ \\
\hline & 4.4 & 884 & 0.371 & $\begin{array}{l}0.639 \pm \\
0.017\end{array}$ & $\begin{array}{l}0.530 \pm \\
0.007\end{array}$ & $\begin{array}{l}0.538 \pm \\
0.049\end{array}$ & $\begin{array}{l}0.441 \pm \\
0.010\end{array}$ & $\begin{array}{l}0.581 \pm \\
0.028\end{array}$ \\
\hline \multirow[t]{9}{*}{ Stones } & 0.5 & 219 & n.a. & $\begin{array}{l}0.130 \pm \\
0.010\end{array}$ & $\begin{array}{l}0.084 \pm \\
0.009\end{array}$ & $\begin{array}{l}0.117 \pm \\
0.009\end{array}$ & $\begin{array}{l}0.087 \pm \\
0.002\end{array}$ & $\begin{array}{l}0.132 \pm \\
0.001\end{array}$ \\
\hline & 0.5 & 864 & n.a. & $\begin{array}{l}0.359 \pm \\
0.040\end{array}$ & $\begin{array}{l}0.240 \pm \\
0.008\end{array}$ & $\begin{array}{l}0.313 \pm \\
0.019\end{array}$ & $\begin{array}{l}0.187 \pm \\
0.003\end{array}$ & $\begin{array}{l}0.277 \pm \\
0.005\end{array}$ \\
\hline & 0.5 & 1813 & n.a. & $\begin{array}{l}0.411 \pm \\
0.032\end{array}$ & $\begin{array}{l}0.342 \pm \\
0.102\end{array}$ & $\begin{array}{l}0.382 \pm \\
0.088\end{array}$ & $\begin{array}{l}0.288 \pm \\
0.053\end{array}$ & $\begin{array}{l}0.369 \pm \\
0.009\end{array}$ \\
\hline & 4.4 & 256 & n.a. & $\begin{array}{l}0.144 \pm \\
0.004\end{array}$ & $\begin{array}{l}0.099 \pm \\
0.002\end{array}$ & $\begin{array}{l}0.138 \pm \\
0.011\end{array}$ & $\begin{array}{l}0.100 \pm \\
0.003\end{array}$ & $\begin{array}{l}0.155 \pm \\
0.007\end{array}$ \\
\hline & 4.4 & 547 & n.a. & $\begin{array}{l}0.306 \pm \\
0.041\end{array}$ & $\begin{array}{l}0.170 \pm \\
0.010\end{array}$ & $\begin{array}{l}0.247 \pm \\
0.007\end{array}$ & $\begin{array}{l}0.167 \pm \\
0.003\end{array}$ & $\begin{array}{l}0.263 \pm \\
0.002\end{array}$ \\
\hline & 4.4 & 1131 & n.a. & $\begin{array}{l}0.466 \pm \\
0.040\end{array}$ & $\begin{array}{l}0.375 \pm \\
0.015\end{array}$ & $\begin{array}{l}0.398 \pm \\
0.033\end{array}$ & $\begin{array}{l}0.248 \pm \\
0.005\end{array}$ & $\begin{array}{l}0.422 \pm \\
0.054\end{array}$ \\
\hline & 13.2 & 32 & n.a. & $\begin{array}{l}0.059 \pm \\
0.013\end{array}$ & $\begin{array}{l}0.050 \pm \\
0.009\end{array}$ & $\begin{array}{l}0.084 \pm \\
0.002\end{array}$ & $\begin{array}{l}0.065 \pm \\
0.001\end{array}$ & n.a. \\
\hline & 13.2 & 102 & n.a. & $\begin{array}{l}0.092 \pm \\
0.004\end{array}$ & $\begin{array}{l}0.095 \pm \\
0.005\end{array}$ & $\begin{array}{l}0.096 \pm \\
0.001\end{array}$ & $\begin{array}{l}0.085 \pm \\
0.001\end{array}$ & $\begin{array}{l}0.088 \pm \\
0.014\end{array}$ \\
\hline & 13.2 & 753 & n.a. & $\begin{array}{l}0.351 \pm \\
0.012\end{array}$ & $\begin{array}{l}0.274 \pm \\
0.005\end{array}$ & $\begin{array}{l}0.374 \pm \\
0.018\end{array}$ & $\begin{array}{l}0.247 \pm \\
0.003\end{array}$ & $\begin{array}{l}0.451 \pm \\
0.059\end{array}$ \\
\hline \multirow[t]{9}{*}{ Synthetic grass } & 0.5 & 94 & 0.025 & $\begin{array}{l}0.084 \pm \\
0.003\end{array}$ & $\begin{array}{l}0.089 \pm \\
0.001\end{array}$ & $\begin{array}{l}0.109 \pm \\
0.002\end{array}$ & $\begin{array}{l}0.052 \pm \\
0.006\end{array}$ & n.a. \\
\hline & 0.5 & 438 & 0.080 & $\begin{array}{l}0.192 \pm \\
0.014\end{array}$ & $\begin{array}{l}0.181 \pm \\
0.006\end{array}$ & $\begin{array}{l}0.225 \pm \\
0.006\end{array}$ & $\begin{array}{l}0.151 \pm \\
0.008\end{array}$ & $\begin{array}{l}0.205 \pm \\
0.005\end{array}$ \\
\hline & 0.5 & 1067 & 0.156 & $\begin{array}{l}0.338 \pm \\
0.006\end{array}$ & $\begin{array}{l}0.299 \pm \\
0.007\end{array}$ & $\begin{array}{l}0.307 \pm \\
0.007\end{array}$ & $\begin{array}{l}0.194 \pm \\
0.025\end{array}$ & $\begin{array}{l}0.255 \pm \\
0.011\end{array}$ \\
\hline & 4.4 & 75 & n.a. & $\begin{array}{l}0.043 \pm \\
0.010\end{array}$ & $\begin{array}{l}0.049 \pm \\
0.005\end{array}$ & $\begin{array}{l}0.072 \pm \\
0.002\end{array}$ & $\begin{array}{l}0.058 \pm \\
0.001\end{array}$ & n.a. \\
\hline & 4.4 & 549 & 0.207 & $\begin{array}{l}0.432 \pm \\
0.009\end{array}$ & $\begin{array}{l}0.312 \pm \\
0.009\end{array}$ & $\begin{array}{l}0.472 \pm \\
0.026\end{array}$ & $\begin{array}{l}0.284 \pm \\
0.009\end{array}$ & $\begin{array}{l}0.339 \pm \\
0.014\end{array}$ \\
\hline & 4.4 & 1103 & 0.417 & $\begin{array}{l}0.688 \pm \\
0.014\end{array}$ & $\begin{array}{l}0.530 \pm \\
0.035\end{array}$ & $\begin{array}{l}0.564 \pm \\
0.030\end{array}$ & $\begin{array}{l}0.371 \pm \\
0.007\end{array}$ & $\begin{array}{l}0.555 \pm \\
0.027\end{array}$ \\
\hline & 13.2 & 52 & n.a. & $\begin{array}{l}0.045 \pm \\
0.002\end{array}$ & $\begin{array}{l}0.036 \pm \\
0.002\end{array}$ & $\begin{array}{l}0.062 \pm \\
0.004\end{array}$ & $\begin{array}{l}0.055 \pm \\
0.002\end{array}$ & n.a. \\
\hline & 13.2 & 202 & 0.118 & $\begin{array}{l}0.175 \pm \\
0.015\end{array}$ & $\begin{array}{l}0.147 \pm \\
0.008\end{array}$ & $\begin{array}{l}0.210 \pm \\
0.014\end{array}$ & $\begin{array}{l}0.147 \pm \\
0.007\end{array}$ & $\begin{array}{l}0.239 \pm \\
0.042\end{array}$ \\
\hline & 13.2 & 1239 & 0.461 & $\begin{array}{l}0.834 \pm \\
0.012\end{array}$ & $\begin{array}{l}0.703 \pm \\
0.075\end{array}$ & $\begin{array}{l}0.752 \pm \\
0.052\end{array}$ & $\begin{array}{l}0.545 \pm \\
0.060\end{array}$ & $\begin{array}{l}0.831 \pm \\
0.006\end{array}$ \\
\hline
\end{tabular}

*Tracer velocities are averages \pm standard deviation of three repetitions; n.a. for not applicable (not able to measure). 
measurement sections. Only the leading edge velocity was estimated for the dye tracer.

\subsubsection{Thermal data}

Thermal data was analysed according to the scheme shown in Fig. 3. A series of 11 thermograms (i.e. thermal images) was extracted from each thermal video: the first corresponded to an instant $\left(t_{0}\right)$ just before the triple tracer addition to the flow and the rest corresponded to the instants $t_{1}$ to $t_{10}$, as the triple tracer in the flow passed through the measurement section $(1.6 \mathrm{~m}$ and 156 pixels length and $0.15 \mathrm{~m}$ and 13 pixels width in a total of 2028 pixels). Fig. $3 a$ shows the images for instant $t_{0}$ and $t_{1}$ to $t_{3}$.

A threshold temperature was established for each series of thermograms, as the maximum flow temperature observed in the instant $t_{0}\left(T_{\text {MAXt0 }}\right)$. The threshold temperature enables the temperatures associated with the tracer to be identified (i.e. pixels with temperature values above the threshold temperature), thus distinguishing them from the other flow temperatures (i.e. pixels with temperature values below the temperature threshold). The threshold temperature was subtracted from the temperature of the thermograms to give the thermograms in Fig. $3 \mathrm{~b}$. It was then possible to specify the position of the leading edge at each instant $\left(\mathrm{P}_{\mathrm{LE}}\right)$, as the first pixel at the front of the thermal tracer (i.e. in X direction) with a temperature value above the threshold temperature and the position of the centroid at each instant $\left(\mathrm{P}_{\mathrm{C}}\right)$, calculated according the moment equation (Eq. (1)):

$P_{C}=\frac{\sum_{x=1}^{156} \sum_{y=1}^{13} T_{x y} \times P_{x y}}{\sum_{x=1}^{156} \sum_{y=1}^{13} T_{x y}}$

where $\mathrm{T}_{\mathrm{xy}}$ is the temperature $\left({ }^{\circ} \mathrm{C}\right)$ of the pixel $\mathrm{xy}$, after subtraction of the threshold value $T_{\text {MAXto }}, P_{x y}$ is the location $(m)$ of the pixel $x y, x$ denotes the direction along the length of the channel (X direction with 156 pixels) and $y$ denotes the direction across the width of the channel (Y direction with 13 pixels).

The velocity of the leading edge (Vthe $\mathrm{LE}_{\mathrm{L}}$ ) and centroid $\left(\mathrm{Vthe}_{\mathrm{C}}\right)$ of the thermal tracer was calculated by dividing the travelled distance $\left(\Delta \mathrm{P}_{\mathrm{LE}}\right.$ and $\Delta \mathrm{P}_{\mathrm{C}}$ in Fig. $\left.3 \mathrm{~b}\right)$ by the time interval between two consecutive instants ( $\Delta$ t in Fig. $3 a)$.

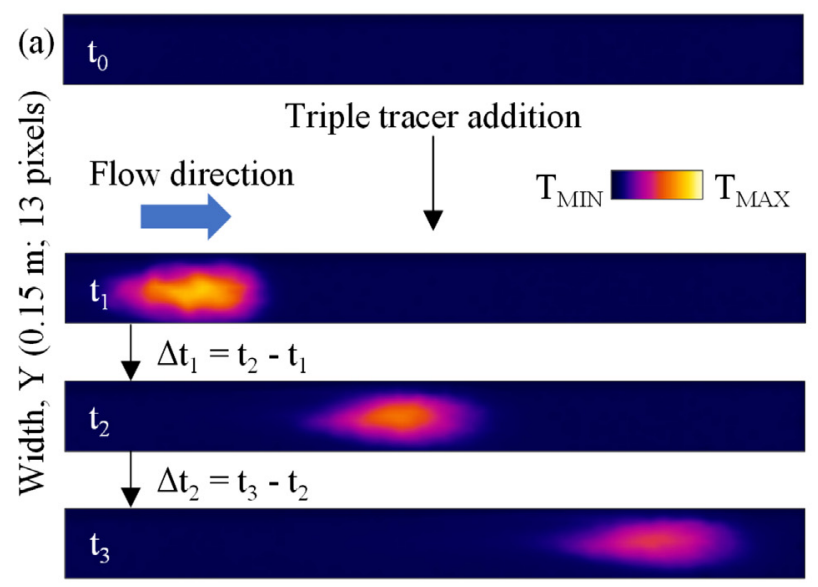

Length, $X(1.60 \mathrm{~m} ; 156$ pixels $)$

\subsubsection{Electrical conductivity data}

Electrical conductivity data was used to measure the velocity of the leading edge $\left(\mathrm{Vsal}_{\mathrm{LE}}\right)$ and centroid $\left(\mathrm{Vsal}_{\mathrm{C}}\right)$ of the salt tracer, as shown in Fig. 4. As with the thermal tracer, a threshold salt concentration was used to distinguish concentrations associated with the tracer from the background flow concentration, and this was subtracted from the measured salt concentration during the passage of tracer. This threshold was set at the maximum salt concentration in the flow observed in the $5 \mathrm{~s}$ before the addition of the tracer $\left(\mathrm{EC}_{\mathrm{MAX} 5 \mathrm{~s}}\right)$. The leading edge $\left(\mathrm{Vsal}_{\mathrm{LE}}\right)$ and centroid (Vsal $\mathrm{C}_{\mathrm{C}}$ ) velocity of the salt tracer was calculated by dividing the distance travelled from the addition of the tracer to the detection section $(2.1 \mathrm{~m})$ by the time taken from the triple tracer addition to the first rise in conductivity above the threshold value (i.e. arrival of the leading edge, $t_{\mathrm{LE}}$ ) and by the time it takes for the centroid of the salt concentration $\left(\mathrm{t}_{\mathrm{C}}\right)$ to arrive, calculated by the moment equation (Eq. (2)):

$\mathrm{t}_{\mathrm{C}}=\frac{\sum_{\mathrm{t}=\mathrm{t}_{\mathrm{LE}}}^{\mathrm{t}_{\mathrm{LE}}+\mathrm{t}_{\mathrm{B}}} \mathrm{EC}_{\mathrm{t}} \times \mathrm{t}}{\sum_{\mathrm{t}=\mathrm{t}_{\mathrm{LE}}}^{\mathrm{t}_{\mathrm{LE}}+\mathrm{t}_{\mathrm{B}}} \mathrm{EC}_{\mathrm{t}}}$

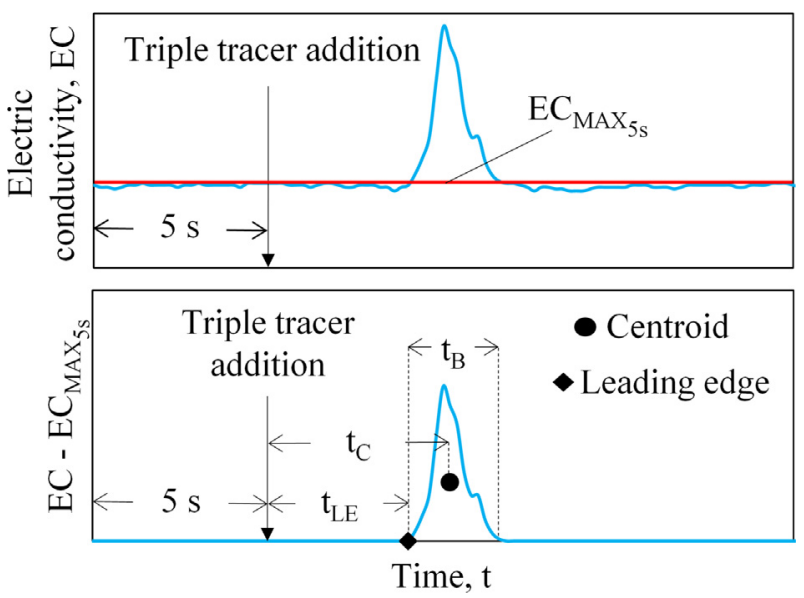

Fig. 4. Scheme of the procedure used in the analyses of the electrical conductivity data for measurement of the flow velocity.

(b)
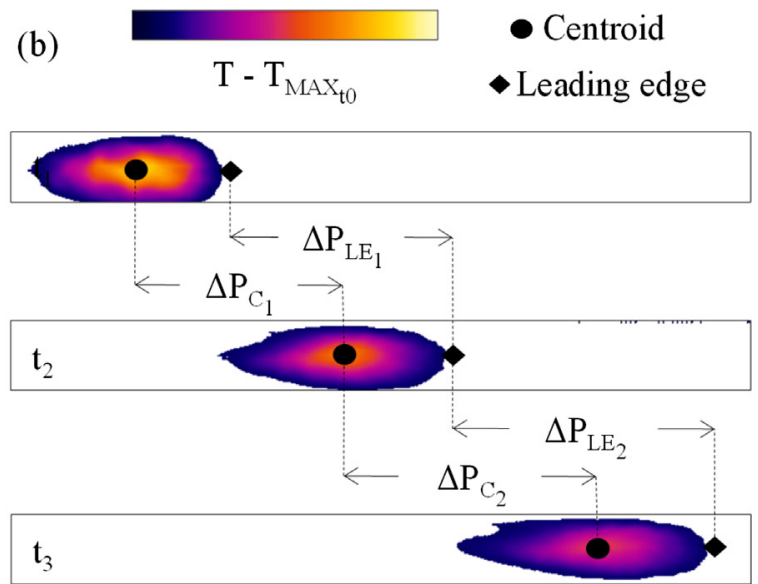

Length, X (1.60 m; 156 pixels)

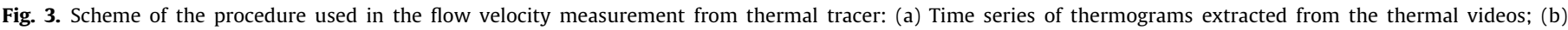
Identification of the leading edge and centroid of the thermal tracer in the flow for flow velocity measurement. 


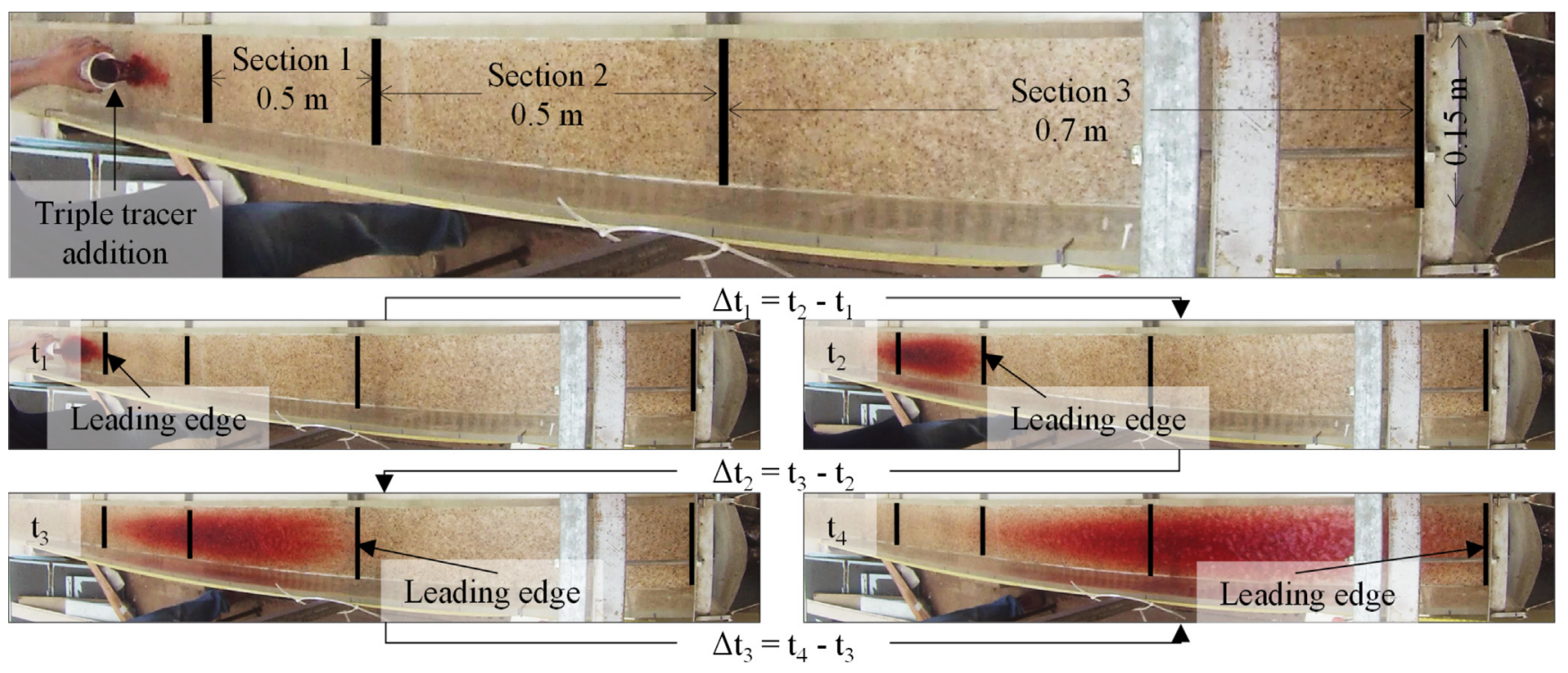

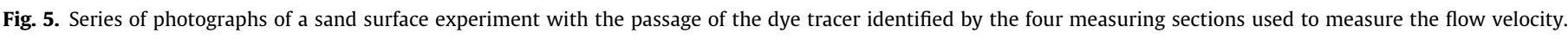

where $\mathrm{EC}_{\mathrm{t}}$ is the electrical conductivity $\left(\mu \mathrm{S} \mathrm{cm}^{-1}\right.$ ) at time $\mathrm{t}(\mathrm{s})$, after subtraction of the threshold value $\mathrm{EC}_{\mathrm{MAX} 5 \mathrm{~s}}$ and $\mathrm{t}_{\mathrm{B}}$ is the base time (s) of the conductivity graphs, from the initial rise in conductivity above the threshold value to the decay below the threshold value.

\subsubsection{Optical data}

For the dye tracer, only the leading edge velocities (Vthe $\mathrm{LE}_{\mathrm{LE}}$ ) were determined, following commonly used procedure, by measuring the travel time of leading edge $(\Delta t)$ during its passage over three measuring sections, as illustrated in Fig. 5. The first two sections were $0.5 \mathrm{~m}$ in length and were at a distance of $0.4-0.9 \mathrm{~m}$ and $0.9-1.4 \mathrm{~m}$ from the triple tracer addition point. The third section was $0.7 \mathrm{~m}$ in length and covered the final stretch of the channel, at a distance of $1.4-2.1 \mathrm{~m}$ from the triple tracer addition point. The travel time was determined from visualizing the real image videos recorded with the optical video camera.

\subsubsection{Flow discharge/depth data}

Flow discharge (measured at the channel outlet) and flow depth (measured with a precision limnimeter) data were used to calculate mean flow velocity ( $\mathrm{Vm}$ ) for all simulated flows, using Eq. (3):

$\mathrm{Vm}=\frac{\mathrm{Q}}{\mathrm{h} \times \mathrm{W}}$

where $\mathrm{Q}$ is the flow discharge $\left(\mathrm{m}^{3} \mathrm{~s}^{-1}\right), \mathrm{h}$ is the measured flow depth $(\mathrm{m})$ and $\mathrm{w}$ is the width of the hydraulic channel ( $\mathrm{m})$.

Mean flow velocity and flow depth were used to calculate the Reynolds number (Re) and Froude number (Fr), according Eqs. (4) and (5) (Emmett, 1970):

$\mathrm{Re}=\frac{4 \times \mathrm{R}_{\mathrm{h}} \times \mathrm{Vm}}{v}$

$\mathrm{Fr}=\frac{\mathrm{Vm}}{\sqrt{\mathrm{g} \times \mathrm{h}}}$

where $R_{h}$ is the hydraulic radius $(m), v$ is the kinematic viscosity of the water $\left(7.842 \times 10^{-7} \mathrm{~m}^{2} \mathrm{~s}^{-1}\right.$ at the average flow temperature of $30.4{ }^{\circ} \mathrm{C}$ observed during the experiments) and $\mathrm{g}$ is the gravitational acceleration $\left(9.807 \mathrm{~m} \mathrm{~s}^{-2}\right.$ ). The hydraulic radius was used instead of the flow depth to calculate the Reynolds number, due to the high flow depth values (reaching almost $1 / 3$ of flow width) in the synthetic grass bed surface tests.

\section{Results and discussion}

\subsection{Triple-tracer velocities}

The triple-tracer experiments outlined in this study allowed the simultaneous measurement of thermal, salt and dye tracer velocity, and consequently the comparison of the three techniques. Table 1 shows results of the triple-tracer experiments, for all simulated flows: leading edge and centroid velocities estimated by thermal $\left(V_{\text {the }} \mathrm{LE}_{\mathrm{E}}\right.$ and $\left.\mathrm{Vthe} \mathrm{C}_{\mathrm{C}}\right)$, salt $\left(\mathrm{Vsal}_{\mathrm{LE}}\right.$ and $\left.\mathrm{Vsal}_{\mathrm{C}}\right)$ and dye $\left(\mathrm{Vdye}_{\mathrm{LE}}\right)$ tracers and mean flow velocities $(\mathrm{Vm})$. Comparison of the tracer velocities is shown in Fig. 6.

In the stone bed surface tests and some of the synthetic grass bed surfaces it was not possible to calculate the mean flow velocity using discharge/depth measurements (n.a. in Table 1), since flow depth measurements failed either because of the size of the stones influenced flow depth or because the flow depths were very shal-

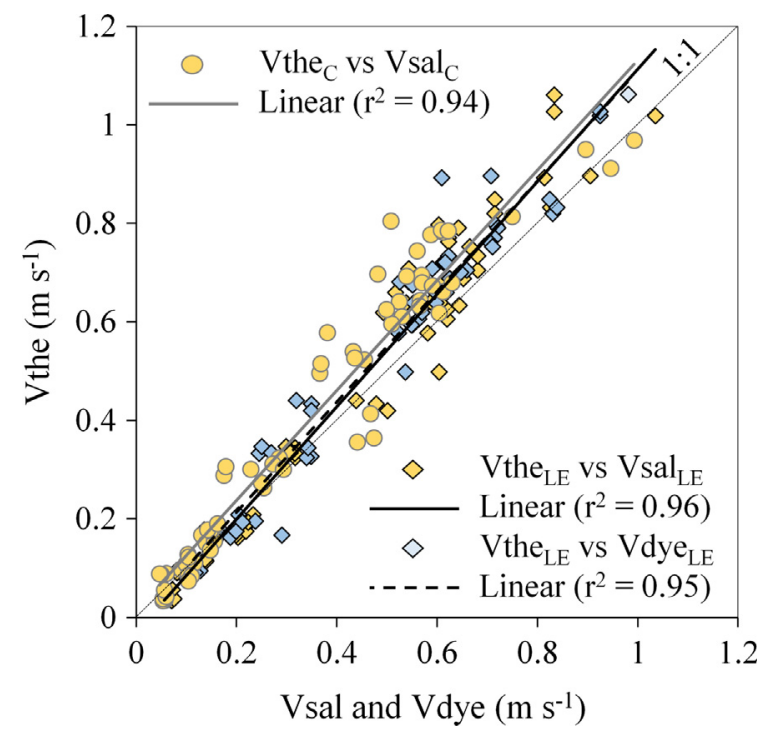

Fig. 6. Comparison between thermal (Vthe), salt (Vsal) and dye (Vdye) tracer velocities for all simulated flows (subscripts LE and C stand for leading edge and centroid, respectively). 
low, sometimes not even covering the stones or the synthetic grass. Thermal tracer velocities for some smaller discharges were also not successfully measured (as discussed below). During the sand bed surface tests of $13.2 \%$ bed slope, the glued sand started to peel off from the acrylic board that was placed over the channel bed; therefore these results were not considered.

As can be seen in Table 1, for the four tested bed surfaces (smooth acrylic, sand, stones and synthetic grass) and three slopes $(0.8,4.4$ and $13.2 \%)$, simulated discharges varied from 32 to 1813 $\mathrm{ml} \mathrm{s}^{-1}$, resulting in measured flow depths from 1.4 to $46.0 \mathrm{~mm}$ and calculated mean flow velocities from 0.02 to $0.85 \mathrm{~m} \mathrm{~s}^{-1}$, Reynolds numbers from 785 to 19,000 and Froude numbers from 0.05 to 4.70.

Thermal, salt and dye tracer techniques yielded very similar results with a good correlation with one another, as can be seen in Fig. $6\left(r^{2}>0.94\right.$ and linear regressions with average angular coefficients of $1.127 \pm 0.011$ and average intercept constants of $0.018 \pm$ 0.008 ). Generally, the thermal tracer technique resulted in slightly higher velocities than the other two techniques, with differences increasing with the measured velocity. Similar results were reported by de Lima and Abrantes (2014b) when comparing dye and thermal tracers. Differences between the thermal and the salt tracing were slightly higher for the centroid velocities.

\subsubsection{Thermal tracer velocities}

Fig. 7 presents results of the thermal tracer flow velocity measurements. Two flow conditions are shown for each tested bed surface, corresponding to the lowest and highest calculated mean flow velocity (see Table 1 ). Two snapshots (time interval of $1 \mathrm{~s}$ ) of the thermal videos of the passage of the thermal tracer along the channel are shown for each flow condition.

The movement of the thermal tracer along the channel was always visible for all simulated flows; however, whereas for higher flow velocities its movement is well defined and well-shaped throughout the channel's length, for lower flow velocities its movement in some cases was only visible during the initial part of the measurement section (e.g. for stone bed surface with a discharge of $32 \mathrm{ml} \mathrm{s}^{-1}$ and a $13.2 \%$ slope). This is related to the nonconservative aspect of the thermal tracer, i.e. temperature diffusion. Lower velocities seem to result in higher temperature diffusion, which can be seen by the dimension of the thermal marks (i.e. pixels with temperature above the threshold value) and maximum temperature values of the tracer $\left(\mathrm{T}_{\mathrm{MAX}}\right.$ in Fig. 7$)$ as it passes along the channel. Overall, lower velocities have lower thermal marks and lower $\mathrm{T}_{\mathrm{MAX}}$. Larger bed roughness elements (e.g. stones) also induced higher tracer diffusion and lower tracer conservation, either by the higher dissipation of flow energy or by heat transfer between flow and the rough element.

One aspect that should be taken into account in the previous observation is that, in general, higher flow velocities were the result of higher discharges and therefore a higher volume of tracer, which facilitates the conservation of the thermal tracer during its passage along the channel. However, for lower flow velocities and lower discharges, the lower volumes of tracer did not facilitate their conservation for the length of the channel. Therefore, one way to improve the conservation of the thermal tracer is to increase the

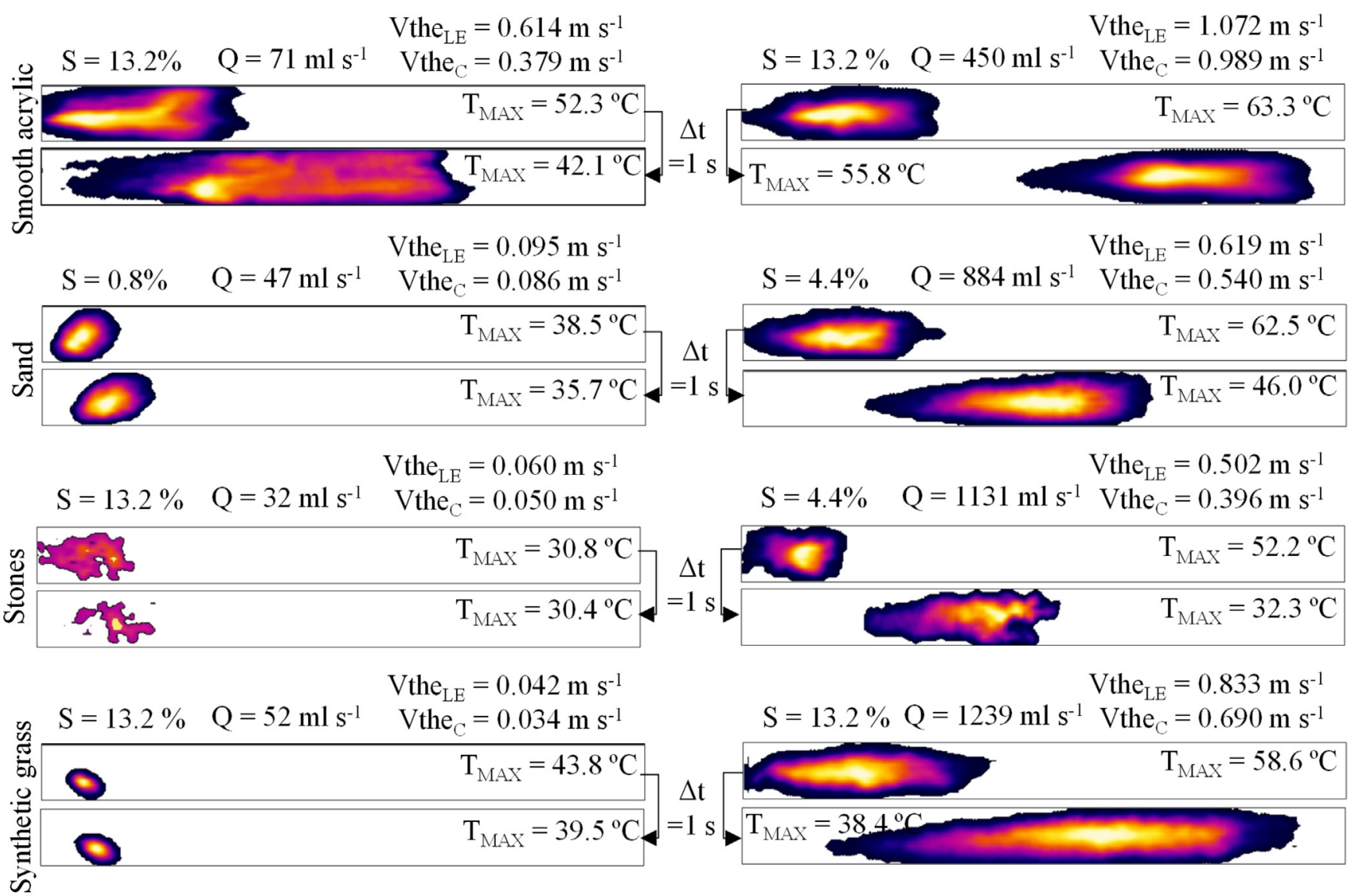

$$
\text { Flow direction } \quad \mathrm{T}_{\mathrm{MAX}_{\mathrm{t} 0}} \approx 30.4^{\circ} \mathrm{C} \quad \mathrm{T}_{\mathrm{MAX}}
$$


volume of added tracer; however, this will increase the error in estimating the flow velocity, since larger volumes of tracer interfere with velocity, especially for smaller discharges where the influence of the volume of added tracer would be more noticeable (de Lima and Abrantes, 2014b; de Lima et al., 2015). Therefore, the optimal volume of thermal tracer will be the smallest amount that permits the application of the technique, i.e. clear visualization of the movement of the tracer in the flow. An alternative to the presented methodology is to introduce a temperature sensor in the water flow instead of using the infrared camera to detect the movement of the thermal tracer; however, introducing a sensor in the water will perturb the flow itself and in these very shallow flows of millimetres to a few centimetres, it is not always possible to properly measure the temperature with a sensor, since these type of sensors usually need a minimum water depth to perform correct measurements.

Another way to diminish the non-conservative aspect of the thermal tracer is by reducing the distance between the tracer addition point and the measuring section; however, this will again increase the error in estimating the flow velocity, since the tracer addition can cause disturbances in the flow that are more noticeable closer to the addition point and for smaller discharges. This can be seen in Fig. 8, which shows that estimated thermal velocities vary with the distance from the tracer addition point. On the one hand, higher velocities closer to the tracer addition point can be caused by the disturbance of the tracer addition, even considering the distance of $0.4 \mathrm{~m}$ between the tracer addition point and the beginning of the measurement area. On the other hand, the nonconservative aspect of the thermal tracer causes a decrease in estimated thermal velocity with increasing distance to the tracer addition point. The tracer temperature decreases as the distance to the tracer addition point increases and, therefore, tracer temperature slowly dissipates in the background water temperature. This effect had more impact on the leading edge velocity (Fig. 8a) than on the centroid velocity (Fig. 8b) because the temperature dissipation occurs first in the interface between the tracer and the water. This effect also increases as bed roughness increases and flow velocity decreases, and is stronger for the stone bed surface and weaker for the smooth acrylic bed surface (i.e. higher heat transfer between flow and the rough element).

Another aspect to be considered when using a thermal tracer is its temperature. A higher tracer temperature will improve the conservation of the tracer without significantly compromising velocity measurements. In previous experiments, de Lima and Abrantes (2014b) found that the relative differences between the leading edge velocities of tracers at 15 and $85{ }^{\circ} \mathrm{C}$ were similar to the relative differences between tracers at the same temperature, as result of the variability induced by the manual addition of the tracer.

\subsubsection{Salt tracer velocities}

Salt transport graphs (i.e. electrical conductivity) recorded at the channel outlet for two flow conditions and the four different tested bed surfaces are shown in Fig. 9 (same tests presented in Fig. 7 for thermal tracer). For all experiments, it was always possible to detect the passage of the salt in the outlet and therefore measure the flow velocity either by the leading edge or the centroid. Unlike the thermal and dye tracers, the salt tracer only gave a one-off measurement of flow velocity.

In general, higher mean velocities (see Table 1) lead to an earlier rise and peak of the salt transport graph, resulting in higher leading edge $\left(V_{s a l}{ }_{L E}\right)$ and centroid velocities $\left(V_{s a l}\right)$. As the estimated salt velocities increased, so did the salt transport peak, while the base transport time (i.e. time from the initial rise in conductivity above the threshold value to the decay below the threshold value) decreased.

The relation between the estimated salt velocities (Vsal ${ }_{\mathrm{LE}}$ and Vsal $_{C}$ ) and the total mass of salt transported by the flow, presented as a ratio of the total mass of salt detected by the electrical conductivity sensor at the channel outlet ( $\left.\mathrm{M}_{\text {transp }}\right)$ to the total mass of salt added to the flow $\left(M_{\text {added }}\right)$, is shown in Fig. 10. Similar to the thermal tracer, the non-conservative aspect of the salt tracer decreases with flow velocity, since salt transport increases. A major concern when using salt tracers to measure flow velocity is how to ensure
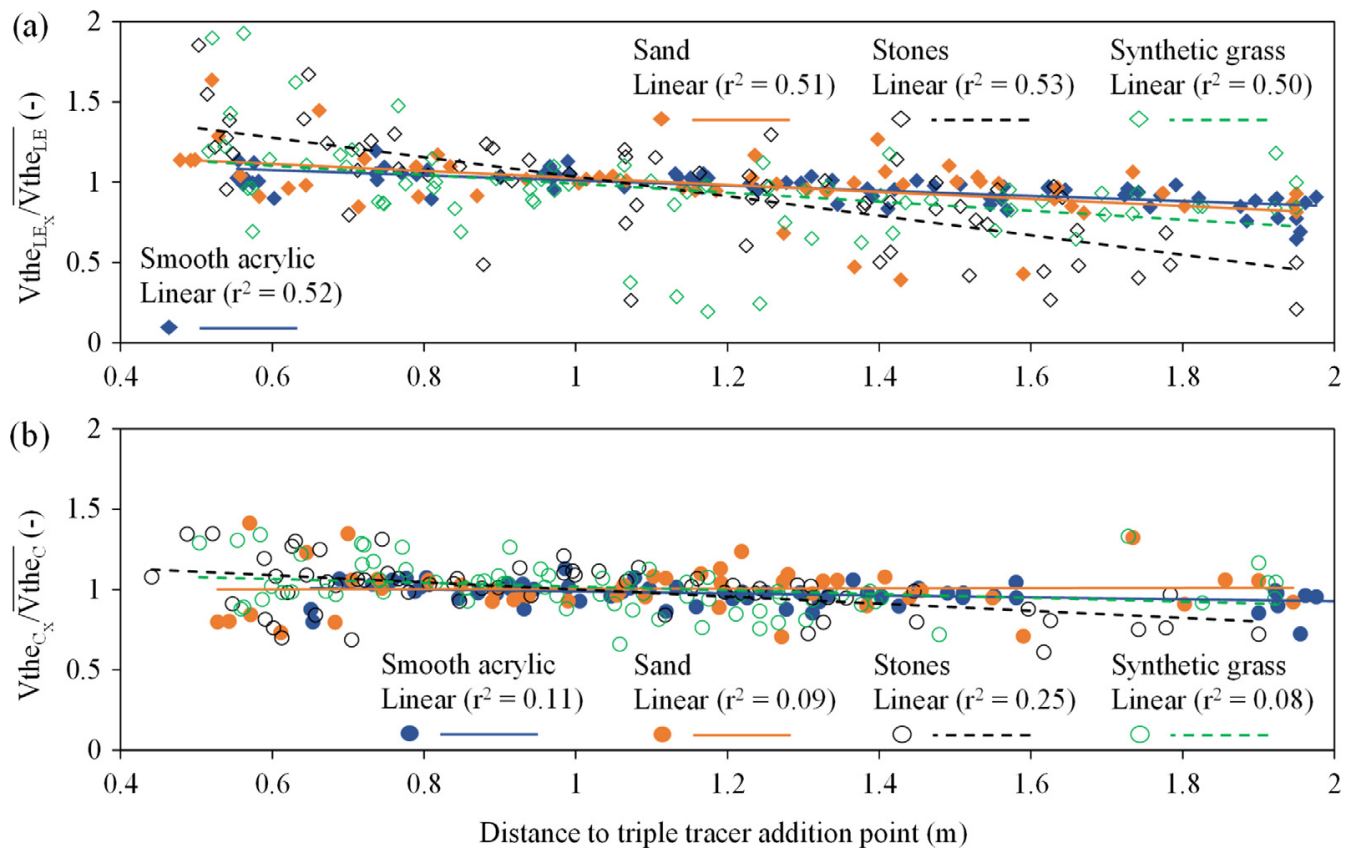

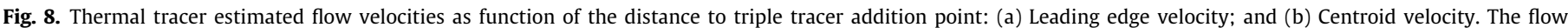

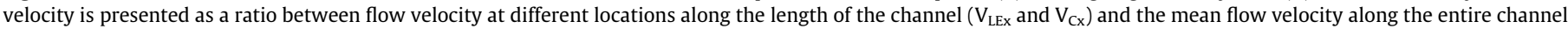
$\left(\mathrm{V}_{\mathrm{LE}}\right.$ and $\left.\mathrm{V}_{\mathrm{C}}\right)$. 

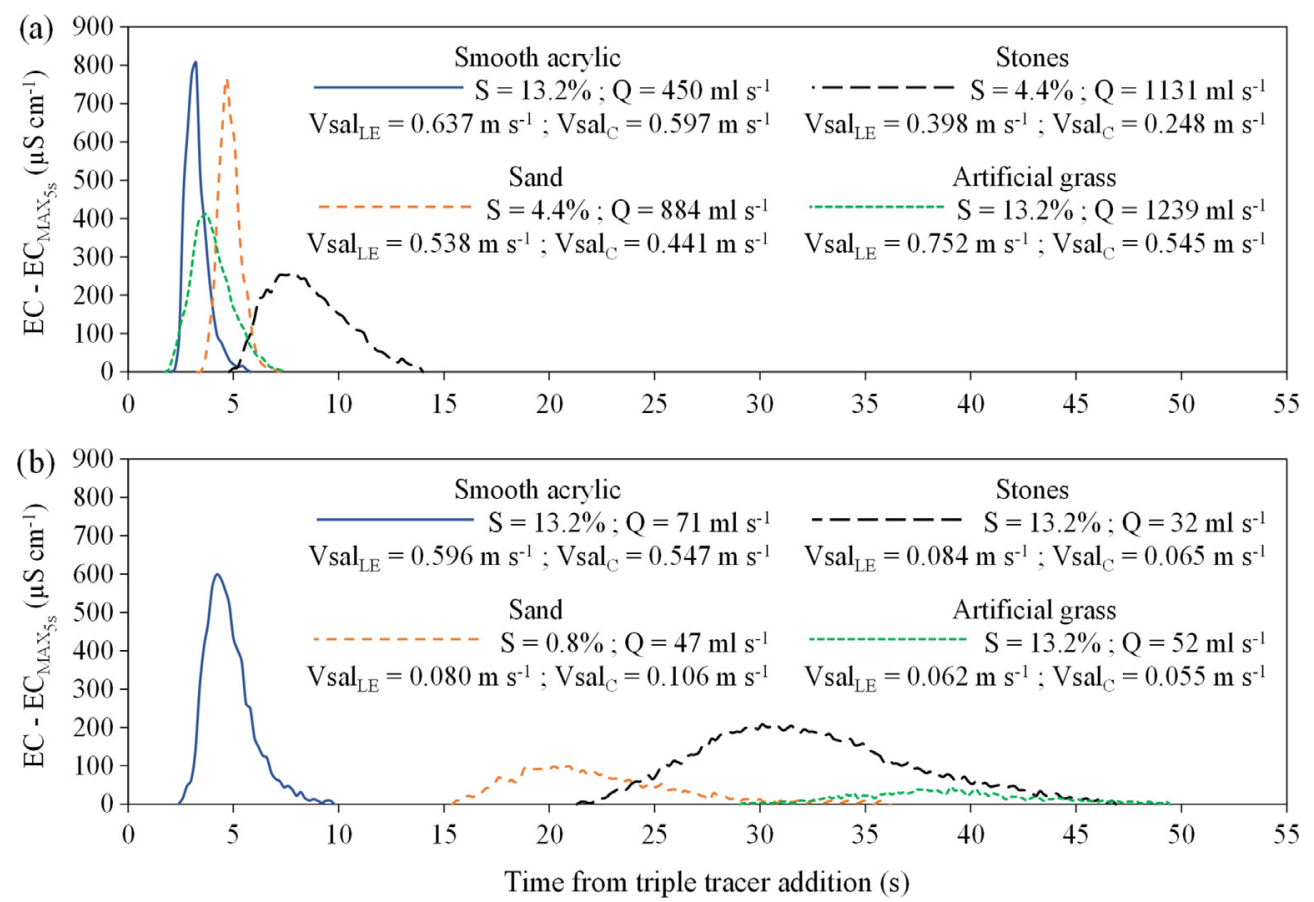

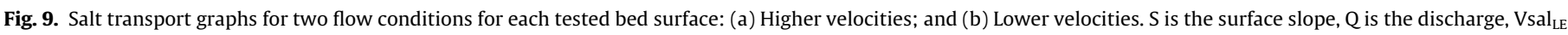
and $\mathrm{Vsal}_{\mathrm{C}}$ are the salt tracer leading edge and centroid velocities, EC is the electrical conductivity and $\mathrm{EC}_{\mathrm{MAX5s}}$ is the threshold electrical conductivity.

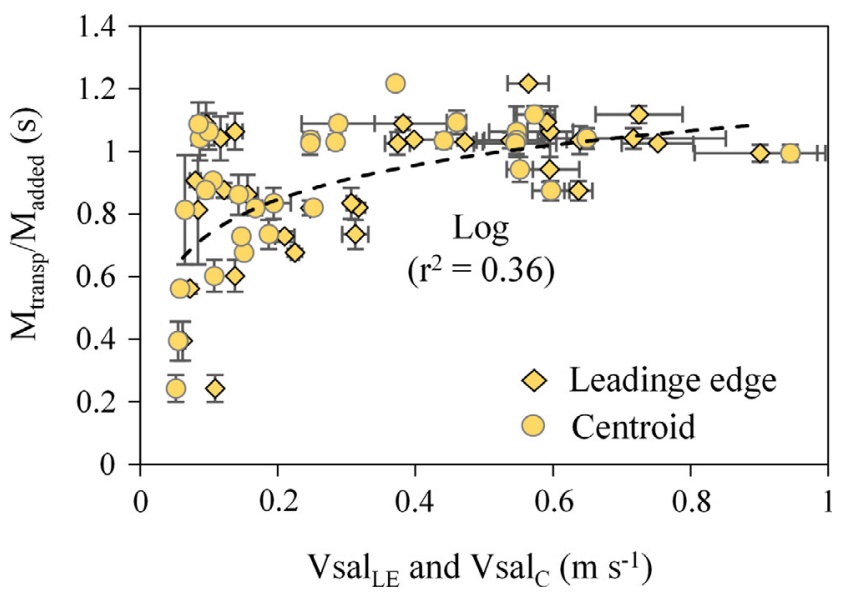

Fig. 10. Relation between estimated leading edge and centroid salt velocities (Vsal ${ }_{\mathrm{LE}}$ and $\left.\mathrm{Vsal}_{\mathrm{C}}\right)$ and the ratio between mass of transported $\left(\mathrm{M}_{\text {transp }}\right)$ and added $\left(\mathrm{M}_{\mathrm{added}}\right)$ salt. Vertical bars indicate standard deviation.

that the salt is completely dissolved in the flow so that it can be properly detected (Day, 1977). In the present study, salt was added as an aqueous solution with hot water, which greatly helped the salt to mix in the flow. Therefore, the decrease of salt transport with lower flow velocity would be closely related to the bed surface roughness. In fact, the average ratio of salt transport for the different tested bed surfaces was $1.02 \pm 0.07,0.85 \pm 0.13,0.87 \pm$ 0.13 and $0.74 \pm 0.30$ for the smooth acrylic, sand, stones and synthetic grass, respectively. One way to improve the conservation of the salt tracer is to increase salt concentration and decrease the distance from the tracer addition point to the sampling point. It should be noted, however, that, similar to the thermal tracer, salt tracer velocities tend to decrease with increasing distance from the salt addition point (Calkins and Dunne, 1970; Planchon et al., 2005). At the same time, higher salt concentration would need a longer mixing time to ensure the salt is properly dissolved in the flow. Therefore, when using a salt tracer, the salt solubility, concentration, addition method (e.g. dry or as an aqueous solution), flow conditions (e.g. discharge, depth, velocity), bed surface roughness and mixing length must all be taken into consideration.

\subsubsection{Dye tracer velocities}

Fig. 11 presents the results of the dye tracer flow velocity measurements (same tests presented in Figs. 7 and 9 for thermal and salt tracers, respectively). Two snapshots of the real image videos of the dye tracer passing along the $0.5 \mathrm{~m}$ measuring section (Section 2 in Fig. 5) are shown for each flow condition.

It was not always possible to estimate flow velocity with the dye tracer for the tested flow conditions. This was because for lower discharges, and thus for lower volumes of added tracer, the dye tracer could not be visualized as it passed along the channel (see Fig. 11 and n.a. in Table 1). This is related to the nonconservative aspect of the dye tracer and, as with the thermal and salt tracers, it was more evident for lower flow velocities in the higher bed surface roughness tests.

One way to increase the conservation of the dye tracer is to increase the dye concentration and decrease the distance from the tracer addition point to the sampling point. But as with the thermal and salt tracers, the dye tracer leading edge flow velocity decreases with increasing distance from the tracer addition point (Fig. 12). Furthermore, timing errors, unavoidable due to human reaction time and the frame rate of the recording system, will tend to increase with shorter measurement lengths (Dunkerley, 2003; de Lima and Abrantes, 2014b). Other way to improve dye tracing performance is to use an automated mechanism of detecting the passage of the dye tracer such as the ones used in Holden et al. (2008) and Dunkerley (2003).

\subsection{Advantages and disadvantages of the tracer techniques}

Overall, the main advantages of the thermal tracer technique over the dye tracer technique were: i) higher visibility of the tracer in the thermal videos compared with the real image videos; ii) esti- 

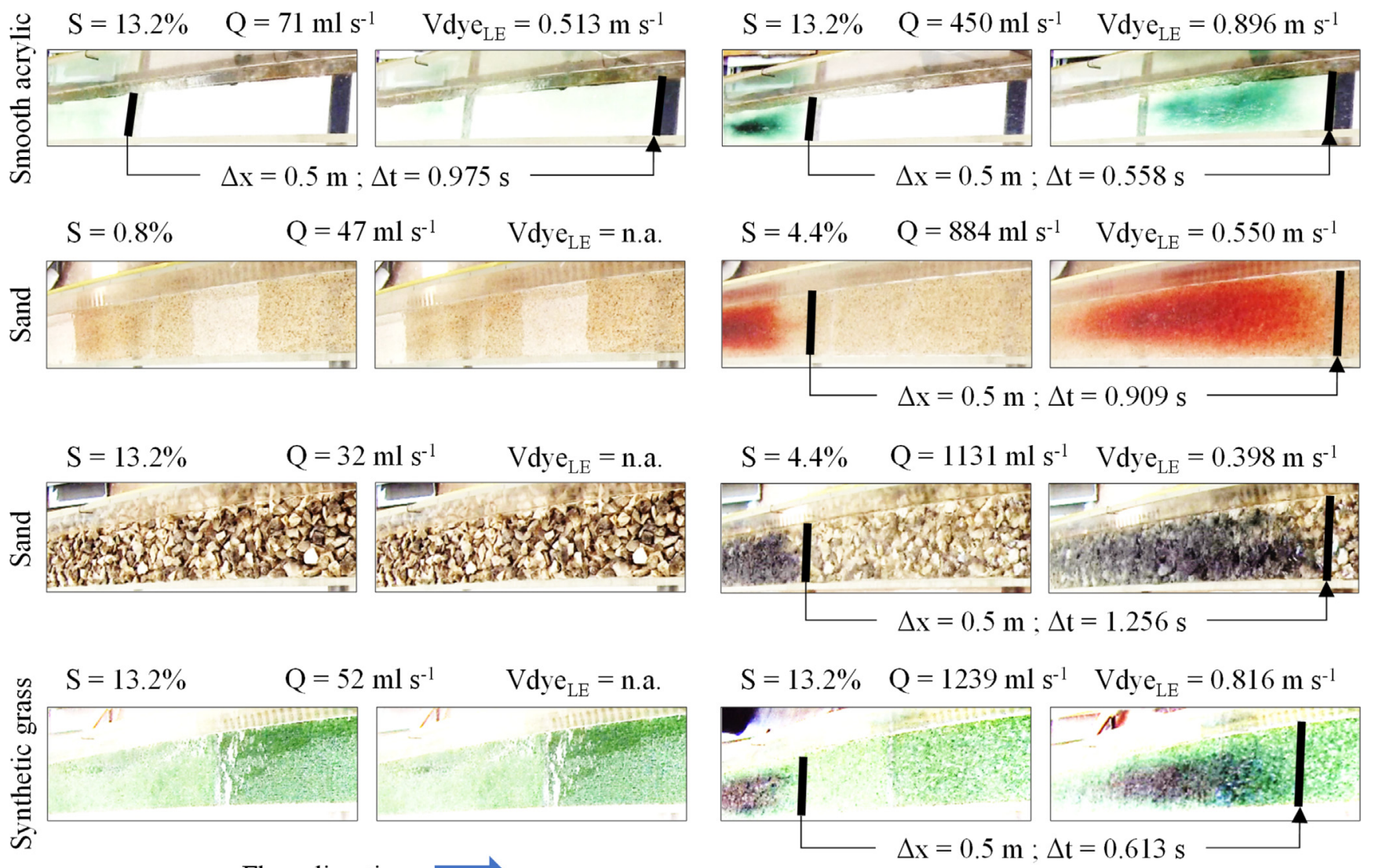

\section{Flow direction}

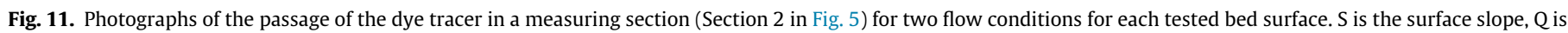
the discharge, Vdye $_{\mathrm{LE}}$ is the dye leading edge velocity, $\Delta \mathrm{x}$ is the measuring section length and $\Delta \mathrm{t}$ is the time interval.

mation of flow velocities using smaller volume of tracer, and, therefore, smaller disturbances in the actual flow velocity; and iii) easy estimation of centroid velocities that are very difficult to obtain from dye tracer measurements, since they require more sophisticated image processing and specific light conditions that may not be always available, especially in field tests. The main advantages of the thermal tracer technique over the salt tracer technique were: i) the visualization of the movement of the thermal tracer along the measuring section; ii) the possibility of measuring space-averaged flow velocities using only one infrared video camera instead of only one velocity value using only one electrolyte sensor (space-averaged salt tracer velocities would require multiple sensors placed along the flume); iii) the possibility of measuring the flow velocity without the need of introducing any instrument (sensor) in the flow, causing less disturbances in the actual flow velocity; and iv) the non-necessity of a minimum water depth, which usually is needed to accurately measure the salt concentration with an electrolyte sensor. The thermal tracer also offers a cleaner and more ecologically friendly way of measuring in situ flow velocities than the dye and salt tracers do, since it leaves no residue in the water or the soil and causes very little temporal and spatial disturbance to the environment.

Overall, the main disadvantages of the thermal tracer technique over the dye and salt tracers techniques were: i) high price of an infrared video camera compared with a regular optical video camera or an electrolyte sensor, despite recent falls in the cost of infrared equipment; and ii) the need to have an energy source to heat or cool the water rather than simply having to add colouring or salt might be an obstacle, especially in remote field studies. The thermal tracer showed less conservation in the flow than the salt tracer and the accuracy of the measurement seemed to depend more on the volume and/or temperature of the tracer than on the concentration of the salt. Measuring flow velocity using the dye tracer can be faster and more intuitive than the thermal tracer, since the movement of the tracer can be simply observed by the operator without using any recording equipment (e.g. camera, sensor), which can be especially useful in field applications.

\section{3. $\alpha$ And $\beta$ correction factors}

Fig. 13 presents the comparison between mean flow velocities $(\mathrm{Vm})$ calculated from flow discharge/depth measurements and the leading edge and centroid velocities measured with the

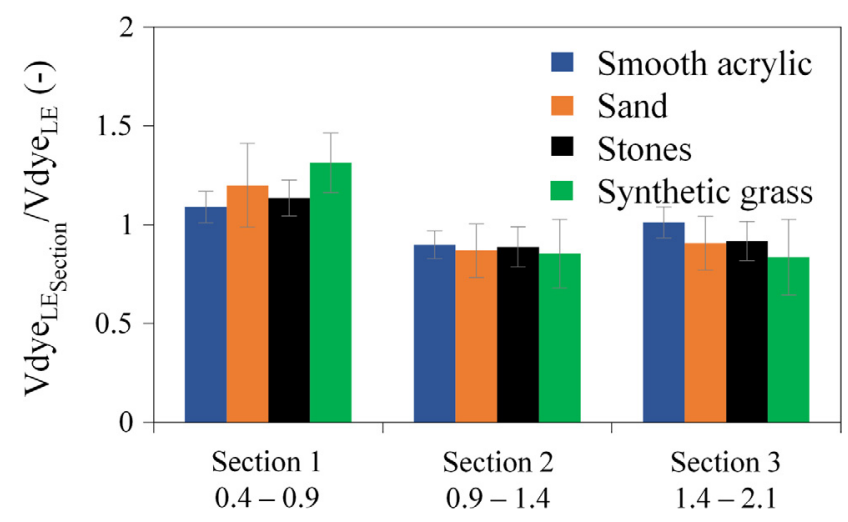

Distance to triple tracer addition point $(\mathrm{m})$

Fig. 12. Ratio between dye tracer leading edge velocities for the three measuring sections $\left(\mathrm{V}_{\mathrm{LESection}}\right)$ and the mean dye tracer velocity along the entire channel $\left(\mathrm{V}_{\mathrm{LE}}\right)$. 


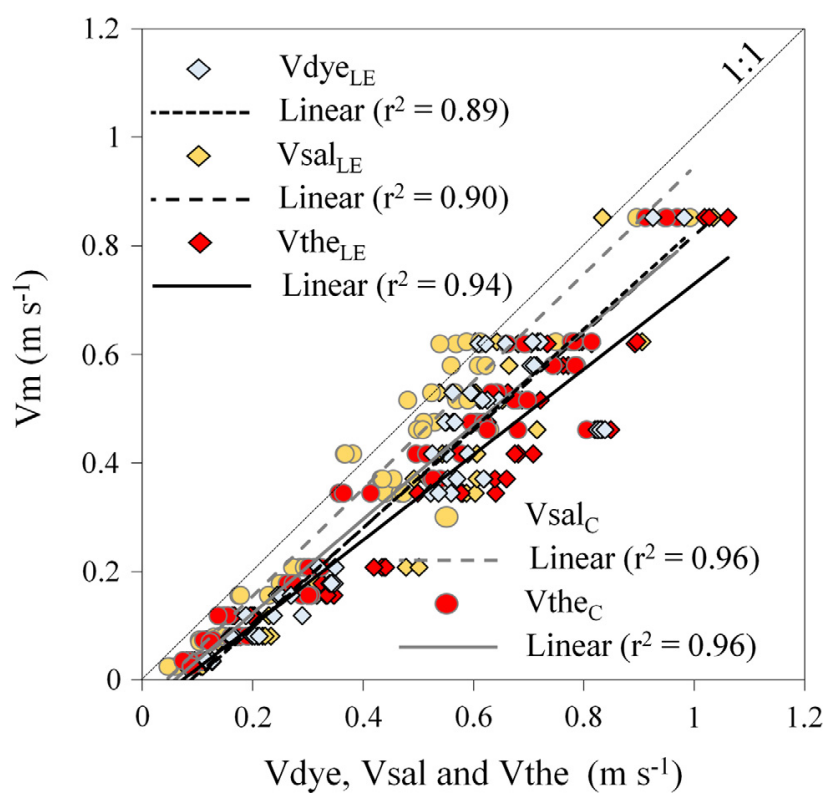

Fig. 13. Comparison between mean flow velocities (Vm) and thermal (Vthe), salt (Vsal) and dye (Vdye) tracer velocities for all simulated flows (subscripts LE and C stand for leading edge and centroid, respectively).

triple-tracer technique. Results of the stone bed surface tests were not considered, since it was not possible to calculate mean flow velocity.

Leading edge and centroid tracer velocities presented a good correlation with mean flow velocity $\left(r^{2}>0.89\right.$ in Fig. 13). As expected, tracer velocities were higher than mean flow velocity, with higher values for the leading edge. In fact, as stated before, leading edge is regarded as the surface velocity of the flow, i.e. the theoretical maximum (or near maximum) value of the flow velocity profile. In turn, centroid velocity is regarded as the theoretical mean value of the flow velocity profile, if conservation of the tracer in the flow is assumed. However, since none of the tracers exhibited absolute conservation during the experiments, centroid velocities were slightly higher than mean flow velocity.

Since tracer velocities were higher than mean flow velocity, a correction factor must be used to convert the measured tracer velocities into actual mean flow velocities. In this study, two correction factors were considered: i) $\alpha$ as the ratio between the mean flow velocity $(\mathrm{Vm})$ and the leading edge velocity measured by means of the triple-tracer technique (Vthe $\mathrm{LE}_{\mathrm{LE}}, \mathrm{Vsal}_{\mathrm{LE}}$ and $\mathrm{Vdye}_{\mathrm{LE}}$ ); and ii) $\beta$ as the ratio between the mean flow velocity (Vm) and the centroid velocity, measured by means of thermal and salt tracers $\left(V_{t h e}\right.$ and $\left.V_{s a l}\right)$. Thermal, salt and dye tracer correction factors $\alpha$ and $\beta$ calculated for the smooth acrylic, sand and synthetic grass (stone bed surface results were not considered) are shown in Fig. 14. As can be seen, there are no significant differences in the $\alpha$ and $\beta$ values for the tracer techniques. Thermal, salt and dye $\alpha$ correction factors ranged from 0.283 to $0.879,0.225-1.034$ and $0.277-1.017$ with average values of $0.595 \pm 0.166,0.626 \pm$ 0.219 and $0.676 \pm 0.193$, respectively. Thermal and salt $\beta$ correction factors ranged from 0.274 to 0.967 and $0.320-1.149$ with average values of $0.666 \pm 0.187$ and $0.774 \pm 0.223$, respectively.

The observed range of $\alpha$ included Horton's theoretical value of 0.67 for an infinitely wide, perfect laminar flow on a smooth and immobile bed (Horton et al., 1934) and the $\alpha$ lower boundary of 0.225 agrees with the range of approximately $0.2-0.9$ found in previous studies (Emmett, 1970; Li et al., 1996; Li and Abrahams, 1997; Dunkerley, 2001; Planchon et al., 2005; Zhang et al., 2010); however, the upper boundary was higher (1.034). For all
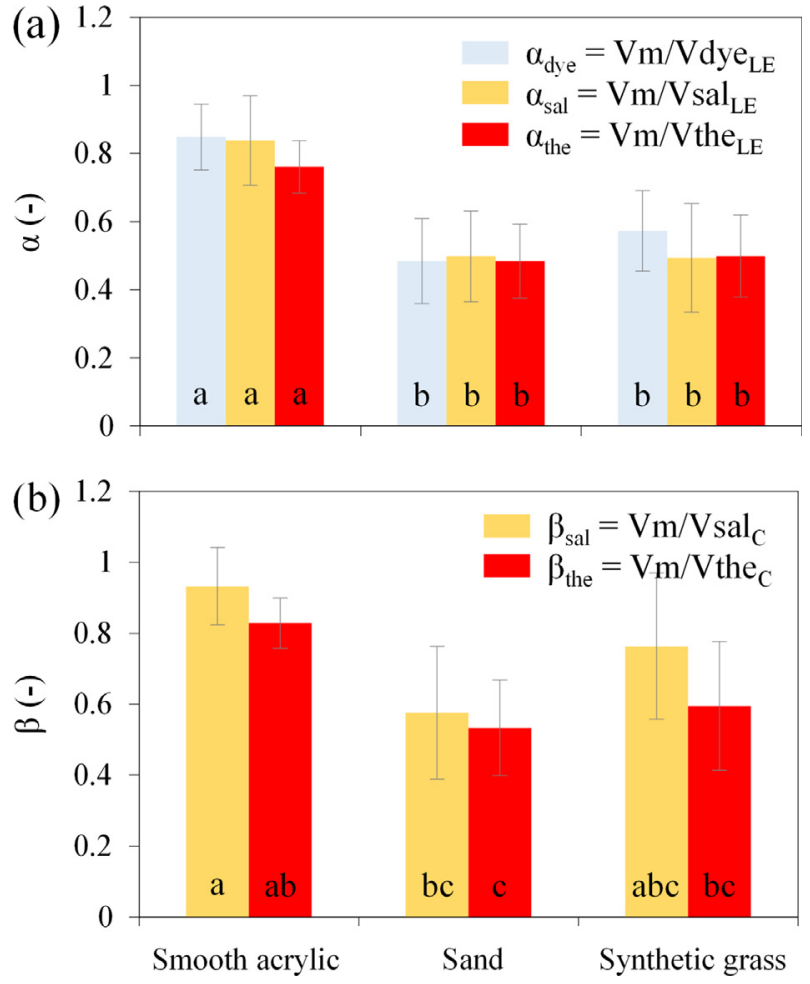

Fig. 14. Correction factors derived from the triple-tracer experiments, for the smooth acrylic, sand and synthetic grass bed surfaces: (a) $\alpha$; and (b) $\beta$. Columns with the same lowercase letter do not differ significantly for Tukey's test $(\mathrm{p}<0.05$ ).

simulated flows, observed $\beta$ values were higher than the $\alpha$ values, which is in line with the theory that tracer centroid velocities are mean theoretical velocities, if conservation of the tracer is assumed. Lower and upper boundaries of $\beta$ (0.274-1.149) exceeded the range of $0.7-0.9$ observed by Li et al. (1996) and $0.6-1.0$ observed by Planchon et al. (2005). However, all previous studies presented a broad variety of findings and conclusions, without actually defining fixed conversion factors or relations. In fact, the variation of $\alpha$ and $\beta$ is the result of a very complex relation between the shape of the flow velocity profile and the flow characteristics (e.g. velocity, depth, Reynolds number, Froude number) and the bed surface characteristics (e.g. roughness, slope).

As shown in Fig. 14, significant differences were found for $\alpha$ and $\beta$ (the latter to a lesser extent) between the smooth acrylic bed surface and the rough bed surfaces (sand and synthetic grass), with $\alpha$ and $\beta$ being smaller for the rough bed surfaces. These findings are in agreement with Emmett (1970) who found smaller $\alpha$ in field experiments than in laboratory experiments, since natural field soil surfaces had a wider range of roughness elements than the laboratory sand surfaces. Roughness elements will perturb the flow and give rise to steeper velocity profiles with a wider gap between the flow velocity profile mean and maximum (i.e. flow surface velocity) values, which implies lower $\alpha$ values. Dunkerley (2001) also observed a tenuous inverse relation between roughness and $\alpha$.

Correction factors increased with increasing Reynolds number (Re) and Froude number (Fr), as shown in Fig. 15. Here, only thermal correction factors are presented, though it should be noted that salt and dye correction factors showed similar behaviour. An increase in $\mathrm{Re}$ and $\mathrm{Fr}$ increases flow turbulence and flow speed, which results in a better mixing of the flow, and a less steep velocity profile, approaching the flow velocity profile mean and maximum values. Therefore, a smaller correction of the tracer velocities is required (i.e. correction factors closer to 1 ). The variation of $\alpha$ and $\beta$ with Re reported in previous studies largely 

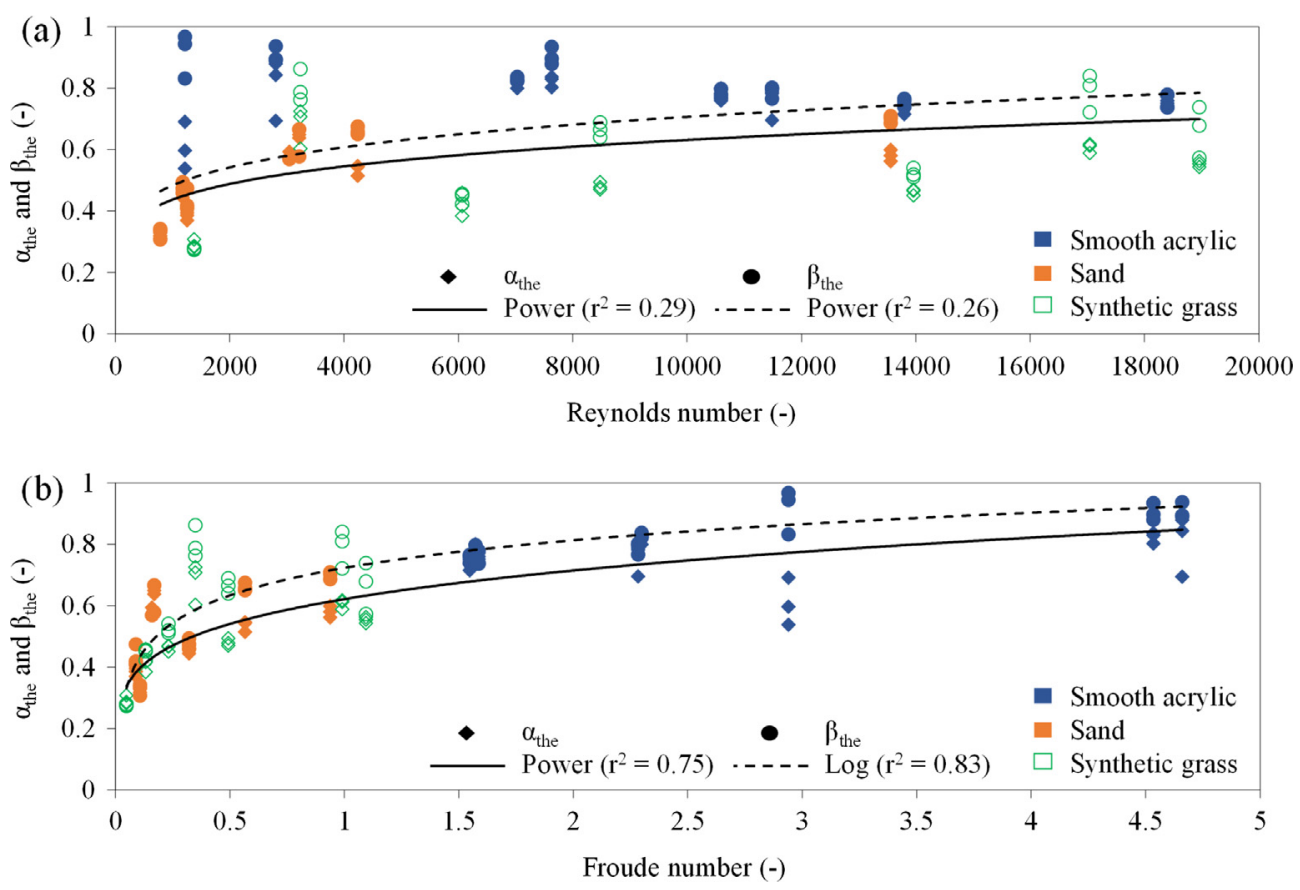

Fig. 15. Variation of thermal $\alpha$ and $\beta$ with: (a) Reynolds number; and (b) Froude number.

depends on the studied flow regime (i.e. range of Re). Emmett (1970) found lower values of $\alpha$ for laminar flow ( $\operatorname{Re}<2000$ ), which increased during transitional flow (Re between 2000 and 8000), with the highest being for turbulent flow $(\operatorname{Re}>8000)$. Li et al. (1996) observed an increase of $\alpha$ and $\beta$ with Re in the transitional flow regime. Li and Abrahams (1997) observed lower values of $\alpha$ in laminar flow, without a distinct trend with Re, a steep rise of $\alpha$ in the transitional flow and a slight rise in the turbulent range. Dunkerley (2001), too, did not find any relation between $\alpha$ and Re in the subcritical laminar range (Re between 100 and 500). In the present study, the variation of $\alpha$ and $\beta$ with Re was tenuous (power regressions with $\mathrm{r}^{2}$ of 0.26 and 0.29 in Fig. 15a) and no clear distinction could be made between the different bed surfaces and the different flow regimes, thus the best fit was achieved when all data was plotted together. Only a slight distinction was found between a rise in the laminar and transitional phase $(\operatorname{Re}<8000)$ and a slight decrease during the turbulent phase $(\operatorname{Re}>8000)$. The rise in the laminar and transitional phase, without any distinction between them, was also noted in Zhang et al. (2010). The slight decrease during the turbulent phase has not been reported in previous studies, but the highest Re studied previously was 13,000 in Li et al. (1996) and in Li and Abrahams (1997) whereas in the present study a maximum of 19,000 was reached.
In the present study, a stronger correlation was found with the variation of $\alpha$ and $\beta$ with the Froude number. Here, the variation of Fr was closely related to the roughness of the surface of the bed; on the smooth acrylic bed surface the flow was supercritical $(\mathrm{Fr}>1)$, with $\mathrm{Fr}$ between 1.60 and 4.70, and on the sand and synthetic grass surfaces the flow varied from subcritical ( $\mathrm{Fr}$ $<1$ ) to critical $(\mathrm{Fr} \approx 1)$, with Fr between 0.05 and 1.09 (Fig. 15b). As stated before, higher roughness leads to lower correction factors. The variation of $\alpha$ and $\beta$ with Fr, was also observed previously in Li and Abrahams (1997) with $\mathrm{Fr}$ varying between 0.4 and 3.2. Such relations were not clear in other studies, e.g. Li et al. (1996) and Zhang et al. (2010) only studied critical to supercritical flow, and Dunkerley (2001) only studied subcritical flow.

Variation of the correction factors with flow velocity, flow depth and bed slope was further analysed. The correction factors $\alpha$ and $\beta$ both increased with flow velocity regardless of the flow regime, as shown in Fig. 16, since these variations were similar for the laminar and turbulent flow and for the subcritical and supercritical flow. Best fit was thus achieved when all data were plotted together. Similar results have been reported in the literature (Emmett, 1970; Li et al., 1996; Li and Abrahams, 1997; Dunkerley, 2001; Planchon et al., 2005; Zhang et al., 2010).

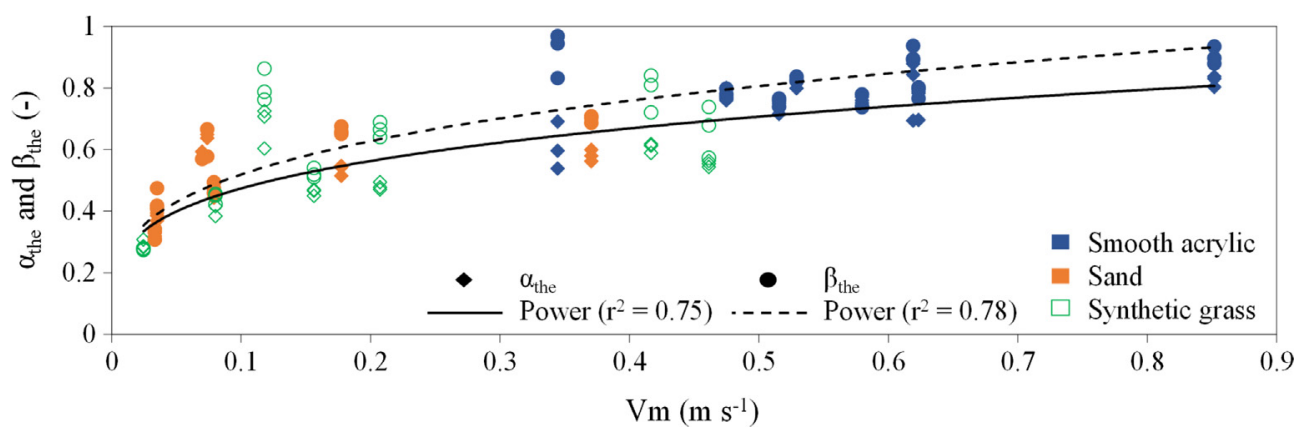

Fig. 16. Variation of thermal $\alpha$ and $\beta$ with mean flow velocity (Vm). 

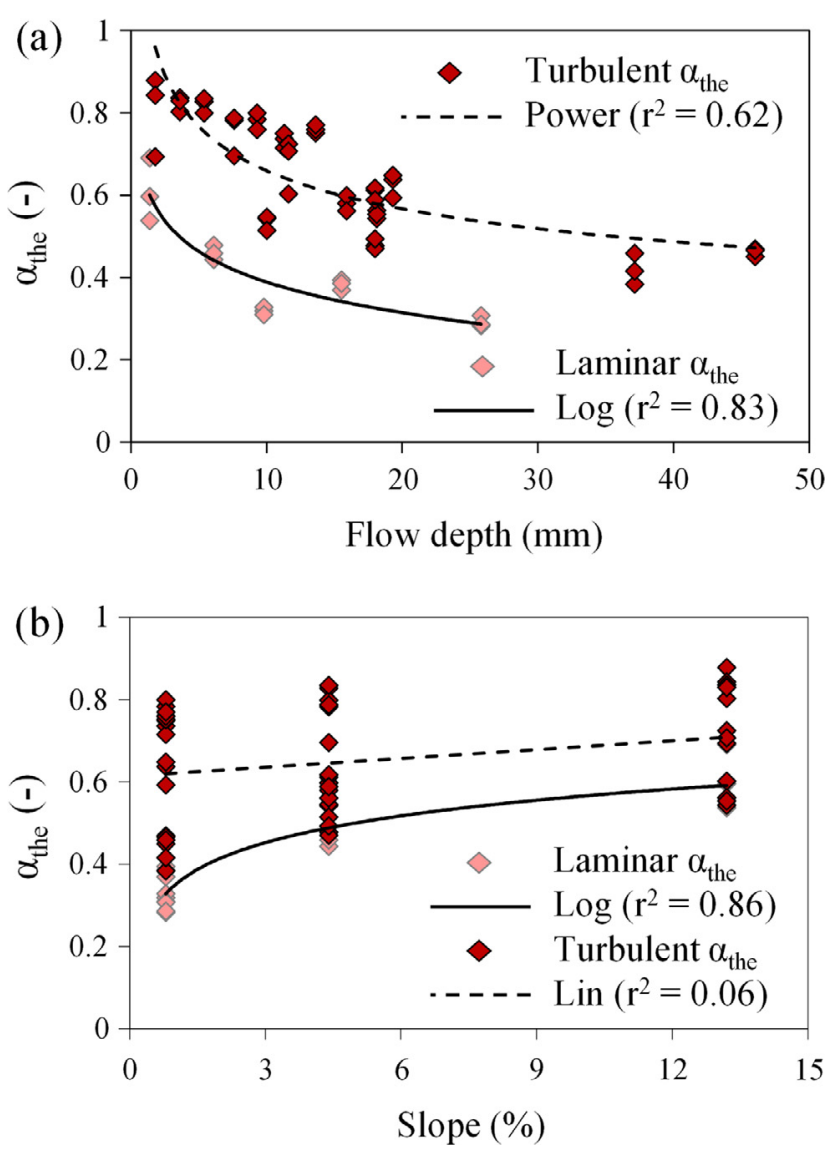

Fig. 17. Graphs for $\alpha$ for laminar and turbulent flows, against: (a) Flow depth; and (b) Bed slope. Turbulent flow includes the transitional phase $(\operatorname{Re}>2000)$.

The variation of $\alpha$ with flow depth and bed slope is shown in Figs. 17 and 18. Here, only $\alpha$ is presented, though it should be noted that $\beta$ showed similar behaviour. These variations depended on the flow regime, since they differed between the laminar and transitional plus turbulent flow. No differences were observed between subcritical and supercritical flow, however. Therefore, best fit was achieved when laminar and transitional plus turbulent data were plotted separately, has shown in Fig. 17. In Fig. 18 data was plotted separately by surface bed. In this situation, best fit was achieved when transitional plus turbulent data was plotted individually. When separating data by bed surface, no clear relation was observed for laminar flow.

In the present study, $\alpha$ decreased with flow depth; this can be attributed to lower flow velocities observed for the rough surfaces that had the higher flow depths. As stated before, higher roughness leads to lower correction factors. The decrease in $\alpha$ with flow depth was also described in Dunkerley (2001) and in Li and Abrahams (1997) for laminar flow. However, in Li et al. (1996), Li and Abrahams (1997) and Zhang et al. (2010) an increase of $\alpha$ with flow depth for transactional and turbulent flow was observed. Each of the three previous studies used only one type of bed surface: smooth acrylic bed surface in Li et al. (1996), and sand bed surface in Li and Abrahams (1997) and Zhang et al. (2010). In the present study, an increase of $\alpha$ with flow depth was only observed for transitional flow on the sand bed surface, as shown in Fig. 18a. In this case, as stated by Zhang et al. (2010), the influence of grain roughness on flow velocity profile may decrease as flow depth increases, resulting in smoother velocity profiles.

The variation of $\alpha$ with bed slope varied considerably with flow regime; while no clear relation was observed for turbulent flow, for
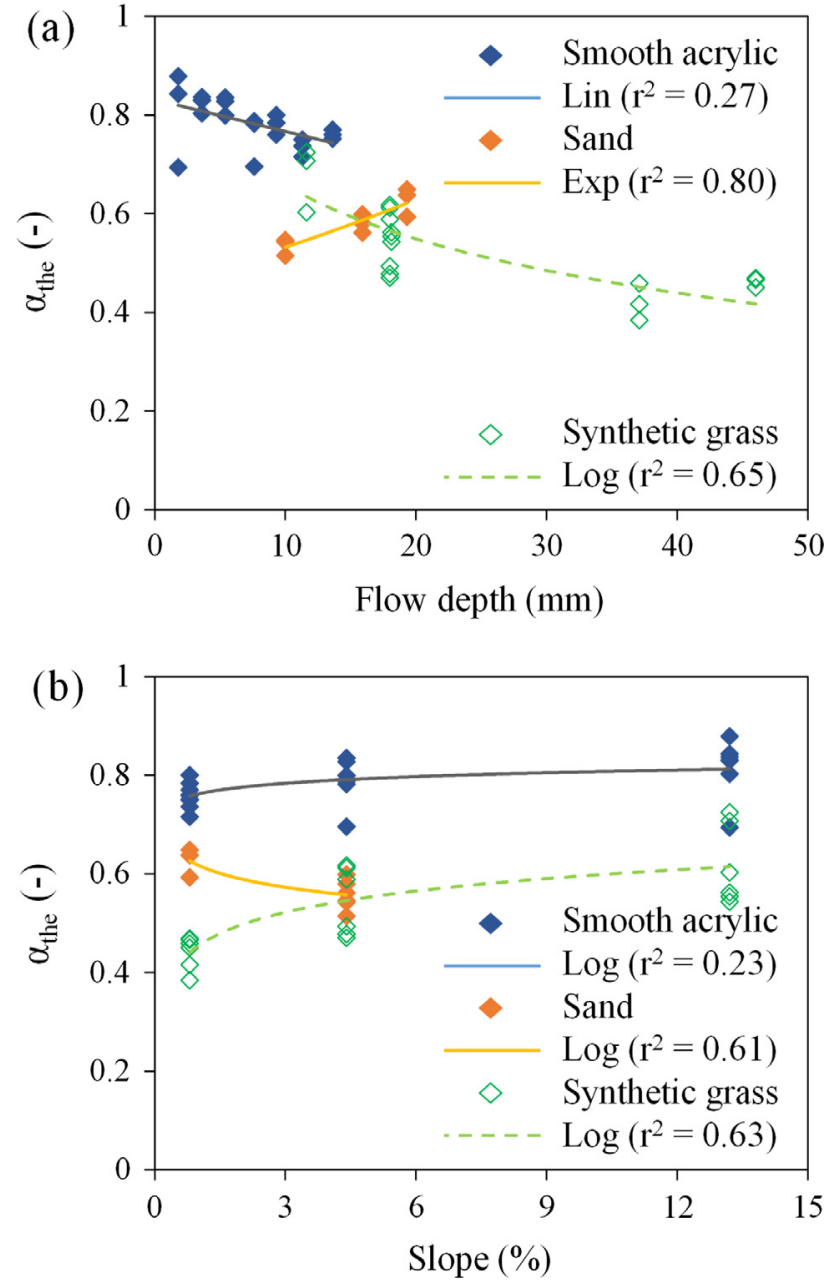

Fig. 18. Graphs for $\alpha$ observed for the turbulent flows in the different bed surfaces, against: (a) Flow depth; and (b) Bed slope. Turbulent flow includes the transitional phase $(\operatorname{Re}>2000)$

laminar flow there was a positive logarithmic relation with good correlation $\left(r^{2}=0.86\right)$. Therefore, slope played an important role in controlling the shape of the flow velocity profile in the laminar range. In fact, for a given flow discharge, as slope gradient increased so did flow velocity, and flow depth decreased. As shown before, an increase in flow velocity results in higher $\alpha$ values. Previous studies had different results; in Li et al. (1996) and Zhang et al. (2010), $\alpha$ decreased with slope for transitional and turbulent flow, but in Li and Abrahams (1997) $\alpha$ did not vary with slope for laminar, transitional or turbulent flow. However, it should be remembered that only one type of bed surface was used in these studies. In the present study, a decrease of $\alpha$ with bed slope was only observed for transitional flow on the sand bed surface, as shown in Fig. 18b.

\section{Conclusions}

To better understand and model the dynamics of sediment and pollutant transport by overland flow, flow velocities must be measured. Traditional dye and salt tracer techniques and the more recent thermal tracer technique have been used to measure flow velocity, especially in shallow muddy overland flows in the field. In this study, a novel triple-tracer approach was tested, using dyed-salted-heated water. This novel approach gave insight into the measurement of shallow flow velocities and proved to be a use- 
ful tool to compare the three techniques. However, it is worth mentioning that despite the improvement achieved by using this triple-tracer approach, many difficulties remained in evaluating shallow flow velocity measurements because of the complexity and spatial and temporal variability of shallow flow. Also, the simultaneous addition of the three tracers may limit each other to their best measurement precisions and the effect of the heated water on dye and salt and vice versa, although presumably minimal, is not fully known.

Results showed that thermal tracing can be used to estimate shallow flow velocities, since the results are similar to those given by other traditional and well-established flow velocity measurement techniques, such as dye and salt tracing. In general, thermal tracer velocities were slightly higher, followed by dye and salt tracer velocities; however, no significant differences were observed between them.

In these triple-tracer experiments, the volume of added tracer was one of the most important limiting factors of the thermal and dye tracer techniques, whereas for the salt tracer this limitation was not so noticeable. It should be noticed that, the ideal volume for each tracer should be different and, therefore, the tripletracer approach may has conditioned the best performance of each method. However, it is also true that the optimal volume of tracer should be the smallest amount that creates the smallest disturbance to the actual flow velocity and, at the same time, permits its clear visualization. In this case, the dye tracer was the less successful technique, since for some lower discharges and lower volumes of added tracer it was not always possible to estimate flow velocity with the dye tracer.

For field applications, the dye tracer technique seems to be faster and simpler, especially if only in situ visual observation is performed (i.e. no recording device). However, the involvement of human perception and reaction time is more prone to timing errors. If an optical video camera is used, the operator should ensure that light conditions are suitable to post imaging analyses, especially if the centroid velocity of the dye tracer is to be measured. For large scale field applications (e.g. hillslope scale) the salt tracer seems to be more appropriate due to the higher conservation. However, the movement of the salt tracer along the measuring section and the possibility of measuring space-averaged flow velocities can only be achieved by installing multiple sensors, which can ultimately cause higher disturbance to the actual flow velocity. Also, many sensors require a minimum water depth that may not be available during shallow flow monitoring. Thermal tracer allows to clearly visualise the movement of the tracer along the measuring section with high accuracy. However, it requires more expensive equipment (i.e. infrared video camera) and an energy source to heat the tracer.

The results showed that the correction factors used to estimate the mean velocity of overland flow from the tracer's leading edge and centroid velocity measurements depend on the flow regime, since they increased with higher Reynolds and Froude numbers. In this study, the correction factors varied directly with flow velocity and slope and inversely with flow depth and bed roughness. In soil erosion and solute transport studies these variables greatly vary in space and time, especially in the field. Therefore, velocity estimation from tracers involves a large amount of uncertainty and caution is required when using these measurements. Data presented in this study can provide new insights on correction factors used in tracing velocity estimation, which is a field not yet clearly understood.

Clear flowing water was used in this study. Further studies are therefore required to investigate the effect of sediment load on the thermal tracer performance and on the respective correction factors. Also, to achieve the best calibration of the thermal tracer technique, further tests should be conducted using different volumes of tracer at different temperatures (hotter and colder water than the flow) and different measuring sections.

\section{Acknowledgements}

This work was supported by FCT, Portugal, and FEDER through the Doctoral grant SFRH/BD/103300/2014 of João Abrantes, the Project HIRT - Modelling surface hydrologic processes based on infrared thermography at local and field scales (PTDC/ECMHID/4259/2014 - POCI-01-0145-FEDER-016668) coordinated by João Pedroso de Lima, and the Strategic project UID/ MAR/04292/2013 granted to MARE, Portugal, and by CNPq, Brazil, through the Post-doctoral grants 451227/2016-6 of Rodrigo Moruzzi and 206872/2014-3 of Alexandre Silveira.

The authors wish to acknowledge the assistance of Iraê Camilo during the execution of the laboratory experiments and Mayara Izumida during the analyses of the real image videos.

\section{References}

Abrahams, A.D., Parsons, A.J., Luk, S.-H., 1986. Field measurement of the velocity of overland flow using dye tracing. Earth Surf. Proc. Land. 11 (6), 653-657. https:// doi.org/10.1002/esp.3290110608.

Abrantes, J.R.C.B., de Lima, J.L.M.P., 2014. Thermography as a remote sensing tool of soil surface microtopography in the presence of mulch. Rev. Bras. Ciênc. Agrár. 9 (3), 445-453. https://doi.org/10.5039/agraria.v9i3a3602.

Abrantes, J.R.C.B., de Lima, J.L.M.P., Prats, S.A., Keizer, J.J., 2017. Assessing soil water repellency spatial variability using a thermographic technique: An exploratory study using a small-scale laboratory soil flume. Geoderma 287, 98-104. https:/| doi.org/10.1016/j.geoderma.2016.08.014.

Abrantes, J.R.C.B., de Lima, J.L.M.P., Prats, S.A., Keizer, J.J., 2016. Field assessment of soil water repellency using infrared thermography. Forum Geographic 15 (2) 12-18. https://doi.org/10.5775/fg.2016.019.s.

Bjerklie, D.M., 2007. Estimating the bankfull velocity and discharge for rivers using remotely sensed river morphology information. J. Hydrol. 341 (3-4), 144-155. https://doi.org/10.1016/j.jhydrol.2007.04.011.

Bjerklie, D.M., Dingman, S.L., Vorosmarty, C.J., Bolster, C.H., Congalton, R.G., 2003 Evaluating the potential for measuring river discharge from space. J. Hydrol 278 (1-4), 13-78. https://doi.org/10.1016/S0022-1694(03)00129-X.

Bonner, R., Aylward, A., Harley, C., Kappelmeyer, U., Sheridan, C.M., 2017. Heat as a hydraulic tracer for horizontal subsurface flow constructed wetlands. J. Water Process Eng. 16, 183-192. https://doi.org/10.1016/j.jwpe.2017.01.007.

Calkins, D., Dunne, T., 1970. A salt tracing method for measuring channel velocities in small mountain streams. J. Hydrol. 11 (4), 379-392. https://doi.org/10.1016/ 0022-1694(70)90003-X

Coz, J.L., Hauet, A., Pieefeu, G., Dramais, G., Camenen, B., 2010. Performance of image-based velocimetry LSPIV applied to flash-flood discharge measurements in Mediterranean rivers. J. Hydrol. 394 (1-2), 42-52. https://doi.org/10.1016/j. jhydrol.2010.05.049.

Day, T.J., 1977. Observed mixing lengths in mountain streams. J. Hydrol. 35 (1-2), 125-136. https://doi.org/10.1016/0022-1694(77)90081-6.

de Lima, J.L.M.P., Abrantes, J.R.C.B., 2014a. Can infrared thermography be used to estimate soil surface microrelief and rill morphology? Catena 113, 314-322. https://doi.org/10.1016/j.catena.2013.08.011.

de Lima, J.L.M.P., Abrantes, J.R.C.B., 2014b. Using a thermal tracer to estimate overland and rill flow velocities. Earth Surf. Proc. Land. 39 (10), 1293-1300. https://doi.org/10.1002/esp.3523.

de Lima, J.L.M.P., Abrantes, J.R.C.B., Silva Jr., V.P., de Lima, M.I.P., Montenegro, A.A.A. 2014a. Mapping soil surface macropores using infrared thermography: Exploratory laboratory study. Sci. World J. 2014, 845460. https://doi.org/ $10.1155 / 2014 / 845460$.

de Lima, J.L.M.P., Abrantes, J.R.C.B., Silva Jr., V.P., Montenegro, A.A.A., 2014 Prediction of skin surface soil permeability by infrared thermography: a soil flume experiment Quant. Infrared Thermogr. 11 (2):161-169. doi:10.1080/ 17686733.2014.945325.

de Lima, J.L.M.P., Silva Jr., V.P., Abrantes, J.R.C.B., Montenegro, A.A.A., de Lima, M.I.P., 2014c. In situ observation of soil macropores using infrared thermography. Die Bodenkultur 64 (3-4), 57-62.

de Lima, R.L.P., Abrantes, J.R.C.B., de Lima, J.L.M.P., de Lima, M.I.P., 2015. Using thermal tracers to estimate flow velocities of shallow flows: laboratory and field experiments. J. Hydrol. Hydromech. 63 (3), 255-262. https://doi.org/10.1515/ johh-2015-0028.

Dunkerley, D., 2001. Estimating the mean speed of laminar overland flow using dye injection-uncertainty on rough surfaces. Earth Surf. Proc. Land. 26 (4), 363-374. https://doi.org/10.1002/esp.185.

Dunkerley, D., 2003. An optical tachometer for short-path measurement of flow speeds in shallow overland flows: improved alternative to dye timing. Earth Surf. Proc. Land. 28 (7), 777-786. https://doi.org/10.1002/esp.468. 
Emmett, W.W., 1970. The Hydraulics of Overland Flow on Hillslopes. Geological Survey Professional Paper 662-A. U.S. Government Printing Office, Washington, D.C., USA.

Flury, M., Flühler, H., 1993. Brilliant Blue FCF as a dye tracer for solute transport studies: a toxicological overview. J. Environ. Qual. 23 (5), 1108-1112. https:// doi.org/10.2134/jeq1994.00472425002300050037x.

Flury, M., Wai, N.N., 2003. Dyes as tracers for vadose zone hydrology. Rev. Geophys. 41 (1), 1002. https://doi.org/10.1029/2001RG000109.

Fulton, J., Ostrowski, J., 2008. Measuring real-time streamflow using emerging technologies: radar, hydroacoustics, and the probability concept. J. Hydrol. 357 (1-2), 1-10. https://doi.org/10.1016/j.jhydrol.2008.03.028.

Giménez, R., Planchon, O., Silvera, N., Govers, G., 2004. Longitudinal velocity patterns and bed morphology interaction in a rill. Earth Surf. Proc. Land. 29 (1), 105-114. https://doi.org/10.1002/esp.1021.

Govers, G., 1992. Relationship between discharge, velocity and flow area for rills eroding loose, non layered materials. Earth Surf. Proc. Land. 17 (5), 515-528. https://doi.org/10.1002/esp.3290170510.

Holden, J., Kirkby, M.J., Lane, S.N., Milledge, D.G., Brookes, C.J., Holden, V., McDonald, A.T., 2008. Overland flow velocity and roughness properties in peatlands. Water Resour. Res. 44 (6), W06415. https://doi.org/10.1029/2007WR006052.

Horton, R.E., Leach, H.R., Vliet, V.R., 1934. Laminar sheet flow. Eos T. Am. Geophys. Un. 15 (2), 393-404. https://doi.org/10.1029/TR015i002p00393.

Kantoush, S.A., Schleiss, A.J., Sumi, T., Murasaki, M., 2011. LSPIV implementation for environmental flow in various laboratory and field cases. J. Hydro-environ. Res. 5 (4), 263-276. https://doi.org/10.1016/j.jher.2011.07.002.

Kimiaghalam, N., Goharrokhi, M., Clark, S.P., 2016. Assessment of wide river characteristics using an acoustic Doppler current profiler. J. Hydraulic Eng. 21 (12), 06016012. https://doi.org/10.1061/(ASCE)HE.1943-5584.0001447.

Kreibich, H., Piroth, K., Seifert, I., Maiwald, H., Kunert, U., Schwarz, J., Merz, B. Thieken, A.H., 2009. Is flow velocity a significant parameter in flood damage modelling? Nat. Hazards Earth Sys. Sci. 9 (5), 1679-1692. https://doi.org/ 10.5194/nhess-9-1679-2009.

Lei, T., Chuo, R., Zhao, J., Shi, X., Liu, L., 2010. An improved method for shallow water flow velocity measurement with practical electrolyte inputs. J. Hydrol. 390 (12), 45-56. https://doi.org/10.1016/j.jhydrol.2010.06.029.

Lei, T., Xia, W., Zhao, J., Liu, Z., Zhang, Q., 2005. Method for measuring velocity of shallow water flow for soil erosion with an electrolyte tracer. J. Hydrol. 301 (14), 139-145. https://doi.org/10.1016/j.jhydrol.2004.06.025.

Leibundgut, C.H., Maloszewski, P., Külls, C.H., 2009. Tracers in Hydrology. John Wiley \& Sons Ltd., Chichester, West Sussex, UK.

Li, G., Abrahams, A.D., 1997. Effect of saltating sediment load on the determination of the mean velocity of overland flow. Water Resour. Res. 33 (2), 341-347. https://doi.org/10.1029/96WR02937.

Li, G., Abrahams, A.D., Atkinson, J.F., 1996. Correction factors in the determination of mean velocity of overland flow. Earth Surf. Proc. Land. 21 (6), 509-515. https:// doi.org/10.1002/SICI1096-983719960621:6<509::AID-ESP613>3.0.CO;2-Z.

Maurice, L., Atkinson, T.C., Williams, A.T., Barker, J.A., Farrant, A.R., 2010. Catchment scale tracer testing from karstic features in a porous limestone. J. Hydrol. 389 (1-2), 31-41. https://doi.org/10.1016/j.jhydrol.2010.05.019.

Mügler, C., Planchon, O., Patin, J., Weill, S., Silvera, N., Richard, P., Mouchea, E., 2011. Comparison of roughness models to simulate overland flow and tracer transport experiments under simulated rainfall at plot scale. J. Hydrol. 402 (1-2), 25-40. https://doi.org/10.1016/j.jhydrol.2011.02.032.

Muste, M., Yu, K., Pratt, T., Abraham, D., 2004a. Practical aspects of ADCP data use for quantification of mean river flow characteristics; Part II: fixed-vessel measurements. Flow Meas. Instrum. 15 (1), 17-28. https://doi.org/10.1016/j. flowmeasinst.2003.09.002.

Muste, M., Yu, K., Pratt, T., Spasojevic, M., 2004b. Practical aspects of ADCP data use for quantification of mean river flow characteristics; Part I: moving-vessel measurements. Flow Meas. Instrum. 15 (1), 1-16. https://doi.org/10.1016/j. flowmeasinst.2003.09.001.

Niazi, A., Bentley, L.R., Hayashi, M., 2017. Estimation of spatial distribution of groundwater recharge from stream baseflow and groundwater chloride. J. Hydrol. 546, 380-392. https://doi.org/10.1016/j.jhydrol.2017.01.032.

Planchon, O., Silvera, N., Gimenez, R., Favis-Mortlock, D., Wainwright, J., Le Bissonnais, Y., Govers, G., 2005. An automated salt-tracing gauge for flowvelocity measurement. Earth Surf. Proc. Land. 30 (7), 833-844. https://doi.org/ 10.1002/esp.1194.

Schuetz, T., Weiler, M., Lange, J., Stoelzle, M., 2012. Two-dimensional assessment of solute transport in shallow waters with thermal imaging and heated water. Adv. Water Resour. 43, 67-75. https://doi.org/10.1016/j. advwatres.2012.03.013.

Shi, X., Zhang, F., Lei, T., Chuo, R., Zhou, S., Yan, Y., 2012. Measuring shallow water flow velocity with virtual boundary condition signal in the electrolyte tracer method. J. Hydrol. 452-453, 172-179. https://doi.org/10.1016/j. jhydrol.2012.05.046.

Takken, I., Govers, G., 2000. Hydraulics of interrill overland flow on rough, bare soil surfaces. Earth Surf. Proc. Land. 25 (13), 1387-1402. https://doi.org/10.1002/ 1096-9837(200012)25:13<1387::AID-ESP135>3.0.CO;2-D.

Tauro, F., Grimaldi, S., 2017. Ice dices for monitoring stream surface velocity. J. Hydro-environ. Res. 14, 143-149. https://doi.org/10.1016/j.jher.2016.09.001.

Tauro, F., Grimaldi, S., Petroselli, A., Porfiri, M., 2012a. Fluorescent particle tracers for surface flow measurements: a proof of concept in a natural stream. Water Resour. Res. 48 (6), W06528. https://doi.org/10.1029/2011WR011610.

Tauro, F., Grimaldi, S., Petroselli, A., Rulli, C., Porfiri, M., 2012b. Fluorescent particle tracers in surface hydrology: a proof of concept in a semi-natural hillslope. Hydrol. Earth Sys. Sci. 16 (8), 2973-2983. https://doi.org/10.5194/hess-162973-2012.

Tauro, F., Pagano, G., Porfiri, M., Grimaldi, S., 2012c. Tracing of shallow water flows through buoyant fluorescent particles. Flow Meas. Instrum. 26, 93-101. https:// doi.org/10.1016/j.flowmeasinst.2012.03.007.

Tauro, F., Porfiri, M., Grimaldi, S., 2014. Orienting the camera and firing lasers to enhance large scale particle image velocimetry for streamflow monitoring. Water Resour. Res. 50 (9), 7470-7483. https://doi.org/10.1002/2014WR015952.

Tauro, F., Porfiri, M., Grimaldi, S., 2016. Surface flow measurements from drones. J. Hydrol. 540, 240-245. https://doi.org/10.1016/j.jhydrol.2016.06.012.

Tazioli, A., 2011. Experimental methods for river discharge measurements: comparison among tracers and current meter. Hydrolog. Sci. J. 56 (7), 13141324. https://doi.org/10.1080/02626667.2011.607822.

Zhang, G.H., Luo, R.T., Cao, Y., Shen, R.C., Zhang, X.C., 2010. Correction factor to dyemeasured flow velocity under varying water and sediment discharges. J Hydrol. 389 (1-2), 205-213. https://doi.org/10.1016/j.jhydrol.2010.05.050. 